\title{
Evaluating the PurpleAir monitor as an aerosol light scattering
} instrument

James R. Ouimette ${ }^{1}$, William C. Malm², Bret A. Schichtel ${ }^{3}$, Patrick J. Sheridan ${ }^{4}$, Elisabeth Andrews $^{4,5}$, John A. Ogren ${ }^{6}$, W. Patrick Arnott ${ }^{7}$

${ }^{1}$ Sonoma Ecology Center, Sonoma Ecology Center, Eldridge, CA 95431, USA

${ }^{2}$ Cooperative Institute for Research in the Atmosphere, Colorado State University, Fort Collins, CO 80523, USA

${ }^{3}$ National Park Service Air Resource Division, Fort Collins, CO 80523, USA

${ }^{4}$ NOAA Global Monitoring Laboratory, Boulder, CO 80305, USA

${ }^{5}$ Cooperative Institute for Research in Environmental Sciences, University of Colorado, Boulder, Colorado 80309, USA

${ }^{6}$ NOAA Global Monitoring Laboratory, Boulder, CO 80305, USA (Retired)

${ }^{7}$ Department of Physics, University of Nevada, Reno, NV 89557, USA

Correspondence to Elisabeth Andrews (betsy.andrews@noaa.gov)

\begin{abstract}
The Plantower PMS5003 sensors (PA-PMS) used in the PurpleAir (PA) monitor PA-II-SD configuration are equivalent to cell-reciprocal nephelometers using a $657 \mathrm{~nm}$ perpendicularly polarized light source that integrates light scattering from 18 to 166 degrees. Yearlong field data at the National Oceanic and Atmospheric Administration's (NOAA) Mauna Loa Observatory (MLO) and Boulder Table Mountain (BOS) sites show that the $1 \mathrm{~h}$ average of the PA-PMS first size channel, labeled " $>0.3 \mu \mathrm{m}$ " ("CH1") is highly correlated with submicrometer aerosol scattering coefficients at the $550 \mathrm{~nm}$ and $700 \mathrm{~nm}$ wavelengths measured by the TSI 3563 integrating nephelometer, from $0.4 \mathrm{Mm}^{-1}$ to $500 \mathrm{Mm}^{-1}$. This corresponds to an hourly average submicrometer aerosol mass concentration of approximately 0.2 to $200 \mu \mathrm{g} \mathrm{m}^{-3}$. A physicaloptical model of the PA-PMS is developed to estimate light intensity on the photodiode, accounting for angular truncation as a function of particle size. Predictions are then compared with yearlong fine aerosol size distribution and scattering coefficient field data at the BOS site. It is shown that $\mathrm{CH} 1$ is linearly proportional to the model-predicted intensity of the light scattered by particles in the PA-PMS laser to its photodiode over 4 orders of magnitude. This is consistent with $\mathrm{CH} 1$ being a measure of the scattering coefficient and not the particle number concentration or particulate matter concentration. Field data at BOS confirm the model prediction that the ratio of $\mathrm{CH} 1$ to the scattering coefficient would be highest for aerosols with median scattering diameters $<0.3 \mu \mathrm{m}$. The PA-PMS detects aerosols smaller than $0.3 \mu \mathrm{m}$ diameter in proportion to their contribution to the scattering coefficient. The model predicts that the PA-PMS response to particles $>0.3 \mu \mathrm{m}$ decreases relative to an ideal nephelometer by about $75 \%$ for particle diameters $\geq 1.0 \mu \mathrm{m}$. This is a result of using a laser that is polarized, the angular truncation of the scattered light, and particle loss in the instrument before reaching the laser. The results of this study indicate that the PA-PMS is not an optical particle counter and that its six size fractions are not an accurate representation of particle size distribution. The relationship between the PA-PMS $1 \mathrm{~h}$ average $\mathrm{CH} 1$ and $\mathrm{b}_{\mathrm{sp} 1}$, the scattering coefficient in $\mathrm{Mm}^{-1}$ due to particles below $1 \mu \mathrm{m}$ aerodynamic diameter, at wavelength 550 nanometers, is found to $b e b_{\text {sp } 1}=0.015 \pm 2.07 \times 10^{-5} \times$ $\mathrm{CH} 1$, for relative humidity below $40 \%$. The coefficient of determination $\mathrm{R}^{2}$ is 0.97 . This
\end{abstract}


suggests that the low-cost and widely used PA monitors can be used to measure and predict the aerosol light scattering coefficient in the mid-visible nearly as well as integrating nephelometers.

Keywords: PurpleAir, Plantower PMS5003, nephelometer, low-cost sensor, physical-optical model, PM2.5, scattering coefficient, visibility, atmospheric aerosol

\section{Introduction}

Currently there are tens of thousands of low-cost aerosol monitors used by atmospheric research groups, air quality monitoring and regulatory organizations, and individual citizen scientists around the world. The recent explosion in the number of these sensors (see, for example, AAQR, 20(2), "Special Issue on Low-cost Sensors for Air Quality Monitoring" and papers therein) is a result of the increased research, regulatory, and citizen interest over the past few years. For example, there are over 9,000 active PurpleAir (PA) aerosol monitors (PurpleAir LLC, Draper, UT), with sampling locations on almost every continent. The large geographic coverage of this array of low-cost sensors presents enormous potential for obtaining valuable information on atmospheric aerosol properties and transport processes.

The majority of these low-cost aerosol sensors are used to monitor the mass concentration of particles with aerodynamic diameters $<2.5 \mu \mathrm{m}$ (PM2.5) (Kelly et al., 2017; Gupta et al., 2018; Sayahi et al., 2018; Zheng et al., 2018; Malings et al., 2019; Barkjohn et al., 2020; Holder et al., 2020; Jayaratne et al., 2020; Mehadi et al., 2020). However, these sensors do not actually measure aerosol mass concentrations but light scattered by the aerosols and thus are dependent on the aerosol particle size distribution, morphology, and composition. Recently, Hagan and Kroll (2020) developed a framework and computer model to estimate the effects of relative humidity and aerosol refractive index on PM2.5 estimated by a number of low-cost sensors. Their model assumed that the low-cost sensor lasers were not polarized and could be modeled with Mie theory. The PMS5003 (PMS) was included in their classification scheme as an example of a sensor that behaved more like a nephelometer than an optical particle counter.

Three recent laboratory studies showed that the PMS response decreases with particle size. He et al. (2020) measured the PMS response to monodisperse ammonium sulfate aerosol particles having diameters of $0.1,0.3,0.5$, and $0.7 \mu \mathrm{m}$. The PMS was able to detect $0.1 \mu \mathrm{m}$ particles. They derived a transfer function that showed that the PMS $>0.3 \mu \mathrm{m}$ channel $(\mathrm{CH} 1)$ response was maximum at particle diameter $0.26 \mu \mathrm{m}$ but decreased significantly below this size. They concluded that the PMS behaved more like a nephelometer than an optical particle counter. Kuula et al. (2020) generated monodisperse dioctyl sebacate oil droplets from 0.5 to $20 \mu \mathrm{m}$ and measured the PMS CH1 response versus particle diameter using an aerosol particle sizer (APS). Their data showed that the PMS relative response decreased for particles $>0.5 \mu \mathrm{m}$ diameter. Tryner et al. (2020) evaluated three low-cost particulate matter sensors, including the PMS, by exposing them to five different types of aerosols in the laboratory. They found that the ratios of PMS-reported to filter-derived PM2.5 mass concentrations were inversely proportional to mass median diameter (MMD). Wood smoke had the smallest MMD, $0.42 \mu \mathrm{m}$; its PMS PM2.5 averaged 2.5 times the filter-derived PM2.5. Conversely, oil mist had the largest MMD, $2.9 \mu \mathrm{m}$; its PMS PM2.5 averaged only 0.23 times the filter-derived PM2.5.

84 Climate modeling requires a robust set of models and atmospheric measurements for predicting 85 anthropogenic aerosol radiative forcing. Currently, there are uncertainties in the modeling 
results, due in part to the sparseness of ground-based data used to evaluate and refine the models (e.g., Gliss et al., 2021). Satellite observations provide global coverage that can be used for model evaluation, but satellite data require further assessment, particularly when trying to provide information about surface aerosol properties. The Surface Particulate Matter Network (SPARTAN) (https://www.spartan-network.org/; Snider et al., 2015) was specifically designed to assess and improve algorithms to relate satellite retrievals to surface aerosols. SPARTAN operates collocated filter-based PM2.5, aerosol scattering coefficient via nephelometer, and aerosol optical depth (AOD) measurements at approximately 20 sites around the world. Model and satellite uncertainties can be reduced using a distributed set of low-cost sensors that can provide aerosol light scattering estimates at a higher spatial and temporal resolution than is possible using nephelometers alone. Low-cost sensors are increasingly being used along with satellite data to estimate global aerosol impacts (Gupta et al., 2018).

There is ongoing scientific debate about the accuracy and precision of these low-cost sensors and their limitations (Morawska et al., 2018; Jayaratne et al., 2020). Many of the recent papers discuss performance evaluations or 'calibrations' of these low-cost sensors by comparing their measurements with traditional, research-grade aerosol measurements (Papapostolou et al., 2017; Barkjohn et al., 2020). The concerns over data quality, stemming largely from inexpensive components, lack of transparency of signal processing, and inadequate quality control and testing at the factory, must be weighed against the advantages of low cost and wide spatial coverage.

The actual measurement in the PA monitor with its two PMS5003 sensors (PA-PMS), and in many other low-cost aerosol monitors, is of light scattered by particles (Kelly et al., 2017), which traditionally has been done in atmospheric research and aerosol monitoring programs using integrating nephelometers. Aerosol light scattering extinction measurements are useful in many applications, including determination of the radiative forcing effects of aerosols on climate change, atmospheric visibility, wildfire/smoke impacts, and validation of model outputs and satellite retrievals (e.g., Malm et al., 1994; Sherman et al., 2015; Snider et al., 2015; Gliss et al., 2021). Even though most low-cost aerosol sensors use light scattering as the basis of their operation, almost none have been evaluated as a low-cost nephelometer to estimate atmospheric light scattering. Markowicz and Chilinski (2020) conducted a 3-year evaluation of two low-cost sensors versus the Aurora 4000 polar integrating nephelometer at a site in southeast Poland. They found that the mass concentration of particles with aerodynamic diameters $<10 \mu \mathrm{m}$ (PM10) from the DfRobot SEN0177 and the Alphasense OPC-N2 were highly correlated $\left(\mathrm{R}^{2}>0.89\right)$ with the aerosol scattering coefficient measured by the nephelometer. They were able to estimate the $1 \mathrm{~h}$ average aerosol scattering coefficient from the low-cost sensors with a root mean square error (RMSE) of $20 \mathrm{Mm}^{-1}$, corresponding to $27 \%$ of the mean aerosol scattering coefficient.

Unfortunately, due to cost, availability, and the expertise required to run them, integrating nephelometers are not operated in great numbers around the world. A recent analysis by Laj et al. (2020) showed 56 long-term monitoring stations reporting their nephelometer data to the World Meteorological Organization (WMO) Global Atmosphere Watch (GAW) World Data Centre for Aerosols. This count includes nephelometers operated in several monitoring networks, including the National Oceanic and Atmospheric Administration's (NOAA) Federated Aerosol Network (NFAN, Andrews et al., 2019), the Aerosols, Clouds and Trace Gases Research Infrastructure (ACTRIS) network (e.g., Pandolfi et al., 2018), and the Interagency Monitoring of 
130 nephelometers in use around the world for short-term field and laboratory studies, the number 131 almost certainly does not exceed a few hundred. This is small compared with the number of low132 cost aerosol monitors in use globally.

133 This paper presents an evaluation of the performance characteristics of the low-cost PA-PMS monitor to measure the integrated aerosol light scattering coefficient. It is shown that the PAPMS sensor configuration is similar to a cell-reciprocal nephelometer. A physical-optical model based on Mie theory and the PMS geometry is created that predicts scattered light intensity on the PMS photodiode and aerosol forward and backward light scattering truncation. Model predictions are then compared with yearlong field data at NOAA's Mauna Loa Observatory (MLO) in Hawaii and the Boulder Table Mountain (BOS) site in Colorado. These PA-PMS measurements are also compared to measured light scattering coefficients, and an empirical relationship is developed to estimate the light scattering and uncertainty from the PA-PMS data.

With a better understanding of what the PA measures, how it works, and its uncertainties, the large network of PA-PMSs could be used to estimate the submicrometer aerosol scattering coefficient at visible wavelengths throughout the world. These data could then be used to improve chemical transport and general circulation models, advance climate change predictions, and provide for better air quality forecasts.

\section{Instrument description}

In this section we first describe the physical and optical characteristics of the PA-PMS to place it in the context of nephelometry. We then provide a brief overview of integrating nephelometers, which are instruments designed specifically to measure light scattering.

\section{1}

\subsection{PA-PMS nomenclature}

The PMS sensor outputs 14 fields that are processed and reported by the PA. Each of these fields will be referred to as a channel. For instance, the PA-reported number concentration of particles $>0.3 \mu \mathrm{m}$ is referred to as $\mathrm{CH} 1$ in the remainder of this paper, number concentrations $>0.5 \mu \mathrm{m}$ as channel two $(\mathrm{CH} 2)$, and so forth. Furthermore, the two PMS sensors embedded in the PA will be referred to as either sensor A or sensor B. Therefore, the number concentration of particles $>0.3 \mu \mathrm{m}$ derived from sensor A will be referred to as $\mathrm{CH} 1 \mathrm{~A}$ and those from sensor $\mathrm{B}$ as $\mathrm{CH} 1 \mathrm{~B}$. The average of $\mathrm{CH} 1 \mathrm{~A}$ and $\mathrm{CH} 1 \mathrm{~B}$ will be referred to as $\mathrm{CH} 1$ avg. The PMS reports the $\mathrm{CH} 1$ units as "\#/dl", which is the number of particles having diameters $>0.3 \mu \mathrm{m}$ per deciliter. In this paper the PMS units for $\mathrm{CH} 1$ are not used.

\subsection{Description of the PA and its PMS 5003 sensors}

The PA monitor integrates two PMS sensors, a Bosch BME280 pressure, temperature, and relative humidity sensor and an ESP 8266 chip (https://www2.purpleair.com/pages/technology). The available specifications of the PMS are incomplete, and the processing algorithms are unknown (He et al., 2020). The following is based on available information and, where needed, professional judgment. Each PMS includes a small laser, a photodiode, a small fan to draw air across the laser, a microprocessor control unit (MCU), and probably an operational amplifier. The MCU processes the signal from the photodiode and outputs the following data fields approximately once per second: $>0.3 \mu \mathrm{m},>0.5 \mu \mathrm{m},>1.0 \mu \mathrm{m},>2.5 \mu \mathrm{m},>5 \mu \mathrm{m},>10 \mu \mathrm{m}$, PM1, PM2.5, and PM10. The PMS denotes the first six data fields as particle number concentrations 
above the designated cutpoint and the last three data fields as mass concentrations of particles below the designated cutpoints; the PM data fields are reported for two different conditions, "standard particles" and "under atmospheric environment". The PA ESP8266 chip calculates 2 min averages of the PMS and BME280 signals. It transmits them wirelessly and writes them as a CSV file on a microSD card.

\subsubsection{Airflow and particle losses}

The recommended orientation of the PA results in aerosol being drawn upward by a small fan through four 3-mm diameter entrance holes in each PMS. The aerosol then enters a $9.4 \mathrm{~cm}^{3}$ chamber (Fig. S1a) and flows upward, parallel to and exposed to the circuit board as shown in Fig. S1b. Particles then make a 180 degree turn through three exit holes at the top of the chamber to emerge on the other side of the circuit board and flow downhill through a channel that is illuminated by the laser. The PMS volumetric flow rate is estimated to be $1.5 \mathrm{~cm}^{3} \mathrm{~s}^{-1}(\sim 0.090$ lpm) based on measurements described in Supplemental Materials Sect. S1. The estimated inlet velocity through the entrance holes is estimated to be $5.3 \mathrm{~cm} \mathrm{~s}^{-1}$.

The PMS inlet orientation 90 degrees to the wind, upward flow, and the low inlet velocity through the sampling holes can result in significant aspiration losses of larger particles (Hangal and Willeke, 1990). Aspiration losses are greater at higher wind speeds because it is more difficult for the larger particles to follow the streamlines into the low velocity PMS inlet. This can result in a lower concentration of larger particles entering the PMS than are in the ambient air. Particle aspiration losses are proportional to the particle Stokes number and the ratio of the wind velocity to the inlet face velocity (Hangal and Willeke, 1990). More details are provided in Supplemental Materials Sect. S1.

At typical wind velocities of $1-3 \mathrm{~m} \mathrm{~s}^{-1}$, the ratio of PMS inlet face velocity to wind speed is only 0.02 to 0.05 , much lower than typical sampling ratios of 0.5 to 6.0 (Kulkarni et al., 2011). Pawar and Sinha (2020) addressed this problem for the Laser Egg low-cost sensor by putting it in a box and adding a $40 \mathrm{lpm}$ fan to increase the inlet-to-wind velocity ratio and to direct the airflow upward to the Laser Egg inlet. During calm winds, large particle aspiration losses may occur by particle gravitational settling, acting against the PMS upward flow (Grinshpun et al, 1993). The actual wind conditions in the ambient air and in the PA near the PMS sample inlet are turbulent. Hangal and Willeke (1990) found in their wind tunnel experiments that turbulence intensity had a negligible effect on aspiration efficiency. Calculations using Eq. S1 (see Fig. S2) predict that at a wind speed of $1 \mathrm{~m} \mathrm{~s}^{-1}$, the PMS aspiration losses for particles $>2 \mu \mathrm{m}$ may be significant. However, it must be cautioned that the literature does not include data for the very low $5.3 \mathrm{~cm} \mathrm{~s}^{-1}$ PMS face velocity and actual measurements of the PMS aspiration efficiencies were not made. They may be significantly different from these calculated efficiencies.

206 Inside the PMS $9.4 \mathrm{~cm}^{3}$ chamber, the air has an average velocity of $0.57 \mathrm{~cm} \mathrm{~s}^{-1}$ and Reynolds 207 number of 6.1, resulting in an average residence time of $6.3 \mathrm{~s}$. The average air velocity in the 208 chamber is equal to the sedimentation velocity of a spherical $10 \mu \mathrm{m}$ diameter particle with a density of $2 \mathrm{~g} \mathrm{~cm}^{-3}$ in air at STP (standard temperature and pressure; values used in this analysis are $273.15 \mathrm{~K}$ and $1010.25 \mathrm{hPa}$, respectively). This suggests that some $2 \mathrm{~g} \mathrm{~cm}^{-3}$ density particles with diameters $>10 \mu \mathrm{m}$ that enter the PMS would settle out in the chamber and not make it to the three exit holes at the top of the chamber. Ultrafine particles can also be lost to the walls of the chamber and the printed circuit board due to convective diffusion. Calculations using the 
214 equation for diffusional losses (Friedlander, 1977) show that less than $1 \%$ of the $0.01 \mu \mathrm{m}$

215 diameter aerosols would be lost in the chamber due to convective diffusion, with even smaller

216 diffusional losses for larger particles.

217 Loss of particles due to inertial impaction on the wall opposite the three holes (Fig. S1b) was

218 estimated by the local air flow Reynolds number near the three holes and the aerosol Stokes number. The local Reynolds number is calculated to be 23, and the Stokes number for $10 \mu \mathrm{m}$ particles is $8.2 \times 10^{-4}$. At these low numbers, the calculated loss to impaction is less than $1 \%$ for all particles less than $10 \mu \mathrm{m}$ diameter (Hering, 1995).

The average flow velocity through the laser beam is approximately $3.0 \mathrm{~cm} \mathrm{~s}^{-1}$. By the time the air flows through the laser beam, it has lost most of the particles over $10 \mu \mathrm{m}$ diameter. Further particle losses due to gravitational settling over the photodiode would be very small, since the gravitational force is parallel to the photodiode.

\subsubsection{Laser}

The wavelength and power of three PMS diode lasers were measured using an Ocean Optics Red Tide USB650 spectrometer and Melles Griot Universal Optical Power Meter, respectively. The wavelength averaged $657+/-1 \mathrm{~nm}$, and the power averaged $2.36+/-0.04 \mathrm{~mW}$. The laser is polarized parallel to the plane of the photodiode detector. This results in the aerosol-scattered light being polarized perpendicular to the plane of incidence. Figure S3 shows that perpendicular polarization results in significantly greater scattering intensity from $0.3 \mu \mathrm{m}$ particles compared to natural or parallel polarization.

The PMS laser beam profile is not a simple plane wave, but complex in shape. The laser has a 3 $\mathrm{mm}$ diameter lens that focuses the laser over the photodiode. The beam profile evolves significantly as it goes through the focal region (Naqwi and Durst, 1990). The laser beam diameter in the laser sensing region over the photodiode was not measured. It was estimated by eye to be 0.5 to $1.0 \mathrm{~mm}$, with significant uncertainty. The PMS MCU turns the laser on and off every $800 \mathrm{msec}$ or $2.5 \mathrm{~s}$, depending on aerosol concentration. The laser pulses are 600-900 msec, with the laser power on continuously during this time. We hypothesize that the PMS MCU gathers data during laser on, processes it during laser off, and uses the difference of the photodiode output during these stages to obtain and subtract any electronic or stray light (other than the laser) background signal to the photodiode.

\section{$244 \quad$ 2.2.3 Photodiode detector}

The actual photodiode model in the PMS is unknown. The photodiode appearance is similar to the BPW34 silicon PIN photodiode. In this paper the specifications of the BPW34 are used to estimate the likely properties of the detector in the PMS. It has a very large dynamic range when operated with reverse bias. The dependence of the photodiode current on the light intensity is very linear over 6 or more orders of magnitude, e.g., in a range from a few nanowatts to tens of milliwatts. Silicon PIN photodiodes have low dark current, a 20 nanosecond rise time, and good wavelength sensitivity between roughly 400 and $1000 \mathrm{~nm}$. (https://www.rpphotonics.com/photodiodes.html). At a wavelength of $657 \mathrm{~nm}$, the BPW34 produces approximately 0.4 microampere current per microwatt of incident radiant power (https://www.fiberoptics4sale.com/blogs/archive-posts/95046662-pin-photodetector- 
characteristics-for-optical-fiber-communication). The PMS does not have any optical elements to capture and focus the aerosol-scattered light on its photodiode.

257 The photodiode does not have a cosine corrector in front and is probably not a true cosine 258 detector. However, the relative spectral sensitivity is advertised to be a cosine response by the manufacturers (https://www.osram.com/ecat/DIL\%20BPW\%2034\%20B/com/en/class pim web catalog 1034 89/prd pim device 2219537/ and https://www.vishay.com/docs/81521/bpw34.pdf).

\section{2}

263

\subsubsection{Laser and photodiode geometry}

The PMS geometry is very similar to a cell-reciprocal nephelometer. Figure 1 shows the PMS laser and photodiode geometry. The distance from the laser exit hole to the light trap is $10 \mathrm{~mm}$; the perpendicular distance from the center of the laser to the photodiode is $1.8 \mathrm{~mm}$; the diameter of the exposed photodiode area is $3.0 \mathrm{~mm}$; and the thickness of the mask over the photodiode is $0.46 \mathrm{~mm}$. $\theta_{1}$ is the lower angular scattering limit, and $\theta_{2}$ is the upper angular scattering limit for a particle in the laser.

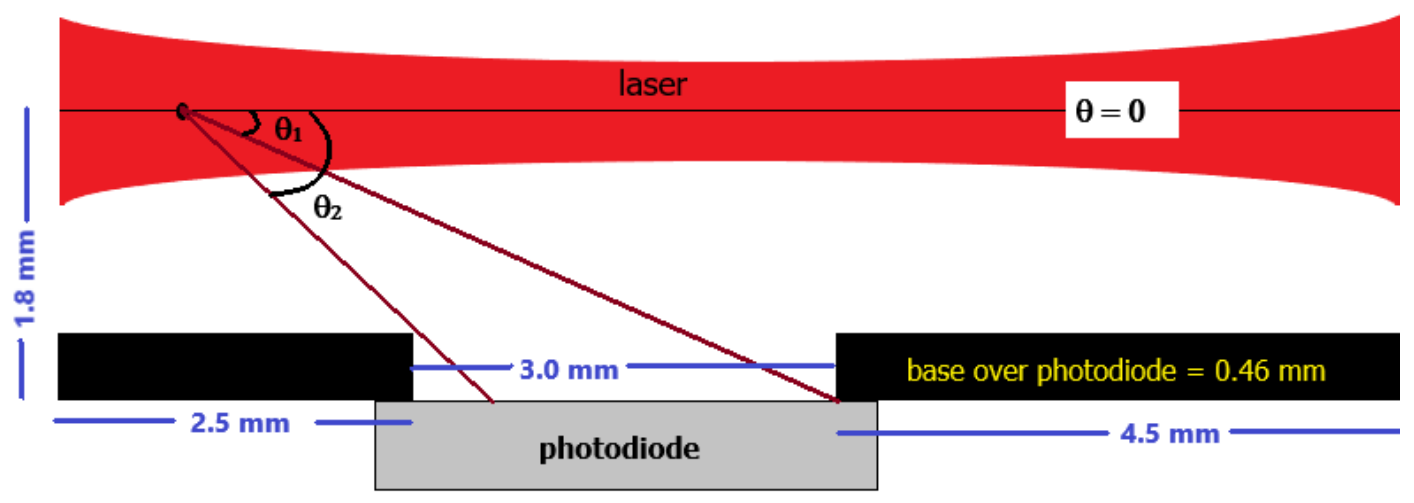

Figure 1. Schematic of the PMS sensor geometry highlighting the dimensions of laser beam (red) and photodiode (gray) and the various relevant distances between the two.

Due to the PMS geometry, the upper and lower angular scattering limits for $\theta$ depend on the location, $x$, of a particle in the laser. This can be seen on Fig. S4. For example, at $x=0 \mathrm{~mm}$, at the laser exit, the upper and lower scattering limits for $\theta$ are $18-38$ degrees. At $x=4.0 \mathrm{~mm}$, over the center of the photodiode, the angular integration limits are 50-130 degrees. The PMS photodiode is not capable of detecting light scattered from particles at less than 18 degrees.

Figures S5-S8 provide more detail about the PMS dimensions and geometry.

\subsubsection{PMS5003 sensing volume}

The sensing volume is the volume in which the aerosol is irradiated by the laser. The sensing volume extends the length of the laser where the aerosol flows through it, approximately $10 \mathrm{~mm}$. The sensing volume is shown in Fig. S9. The average residence time of a particle in the laser 
beam is approximately $0.03 \mathrm{~s}$. Some of the scattered light is detected by the photodiode and creates a voltage pulse approximately $30 \mathrm{msec}$ wide. It appears that the photodiode is detecting either a cloud of particles from the sensing volume or individual pulses, depending on the concentration. At low concentrations, the aerosol concentration within the sensing volume is unlikely to be uniform, resulting in large relative changes in output per second.

\subsubsection{Signal processing and electronics}

It is not known how the PMS MCU differentiates and processes the photodiode signals. The PMS MCU sends the PA a signal approximately every second in the form of a digital sequence of unsigned 16 bit binary data words, and $\mathrm{CH} 1$ is thought to be proportional to the photodiode current. The photodiode current was not measured in this study. The PA creates $80 \mathrm{~s}$ (Firmware Version 3) or $120 \mathrm{~s}$ (Firmware Version 4 and higher) averages and writes them to its microSD card. We measured an average percentage difference of $0.3 \%$ between the 2 min averages reported by the PA and the 2 min averages calculated from the $1 \mathrm{~s}$ values from the PMS. The results are shown in Fig. S10. It is apparent that the processing done by the PA to calculate its reported 2 min averages does not bias the results.

\subsubsection{PMS CH1 variability in sampling filtered air}

We found significant variability in PMS response to filtered air. We exposed 21 PAs containing 42 PMS sensors to filtered air for 2 to 94 hours. The results are summarized in Table S1. Hourly average $\mathrm{CH} 1$ ranged from 0.10 to 377 . Eleven PAs had both PMS CH1A and CH1B averages below 2, while seven PAs had at least one $\mathrm{CH} 1$ average over 26 . We recommend that before deployment the PAs sample filtered air for at least 4 hours to identify and eliminate PAs with $\mathrm{CH} 1$ hourly averages over 2 in filtered air. Removing PAs with high $\mathrm{CH} 1$ offsets in filtered air reduces uncertainty and improves precision, particularly in cleaner ambient air.

\subsubsection{PMS CH1 unresponsive to $\mathrm{CO}_{2}$ and Suva ${ }^{\circledR}$}

Filtered air, $\mathrm{CO}_{2}$, and Suva ${ }^{\circledR}$ (DuPont ${ }^{\mathrm{TM}}$ Suva ${ }^{\circledR} 134 \mathrm{a}$ refrigerant) are often used to calibrate integrating nephelometers (Anderson et al., 1996). The Rayleigh scattering coefficients of filtered air, $\mathrm{CO}_{2}$, and Suva at $657 \mathrm{~nm}$ and at STP $\left({ }^{\circ} \mathrm{C}\right.$ and $\left.1013.25 \mathrm{hPa}\right)$ are 5.5, 13.3, and 46.2

$309 \mathrm{Mm}^{-1}$, respectively. We found that the PMS was unresponsive to $100 \% \mathrm{CO}_{2}$ (Fig. S11) and Suva. The $\mathrm{CH} 1$ for each gas was the same as filtered air. These results indicate that the PMS signal processing zeroes out a constant scattering signal and cannot be used to measure the scattering coefficient of gases that are commonly used in calibrating nephelometers. Furthermore, the method used by the PMS to subtract light scattering by air molecules in the sampling volume is unknown.

\section{$315 \quad$ 2.2.9 PMS CH1 and CH1avg precision}

316 The PMS CH1 precision was measured by collocating ten PA monitors on the roof of the NOAA 317 building in Boulder, Colorado, between 22 January 2021 and 1 February 2021. These monitors 318 were not checked with filtered air before deployment. It was found that two of the PMS sensors 319 had large offsets and two had moderate offsets at low CH1 values. One PMS sensor was found to 320 produce errant data and was removed from the analysis, resulting in valid data from $19 \mathrm{CH} 1 \mathrm{~A}$ 321 and CH1B sensors in the ten PAs. 
The hourly $\mathrm{CH} 1 \mathrm{~A}-\mathrm{CH} 1 \mathrm{~B}$ and $\mathrm{CH} 1 \mathrm{avg}$ precisions were estimated as the coefficient of variation for the $19 \mathrm{CH} 1 \mathrm{~A}-\mathrm{CH} 1 \mathrm{~B}$ and $9 \mathrm{CH} 1$ avg values for each hour, which are plotted against the average $\mathrm{CH} 1$ values in Fig. 2. As shown, above $\mathrm{CH} 1$ values of 500, the precision is relatively constant with an average of $8 \%$ and $4.8 \%$ for $\mathrm{CH} 1 \mathrm{~A}-\mathrm{CH} 1 \mathrm{~B}$ and $\mathrm{CH} 1 \mathrm{avg}$, respectively. Below $\mathrm{CH} 1$ values of 500, the uncertainties increase rapidly with decreasing $\mathrm{CH} 1$ values.
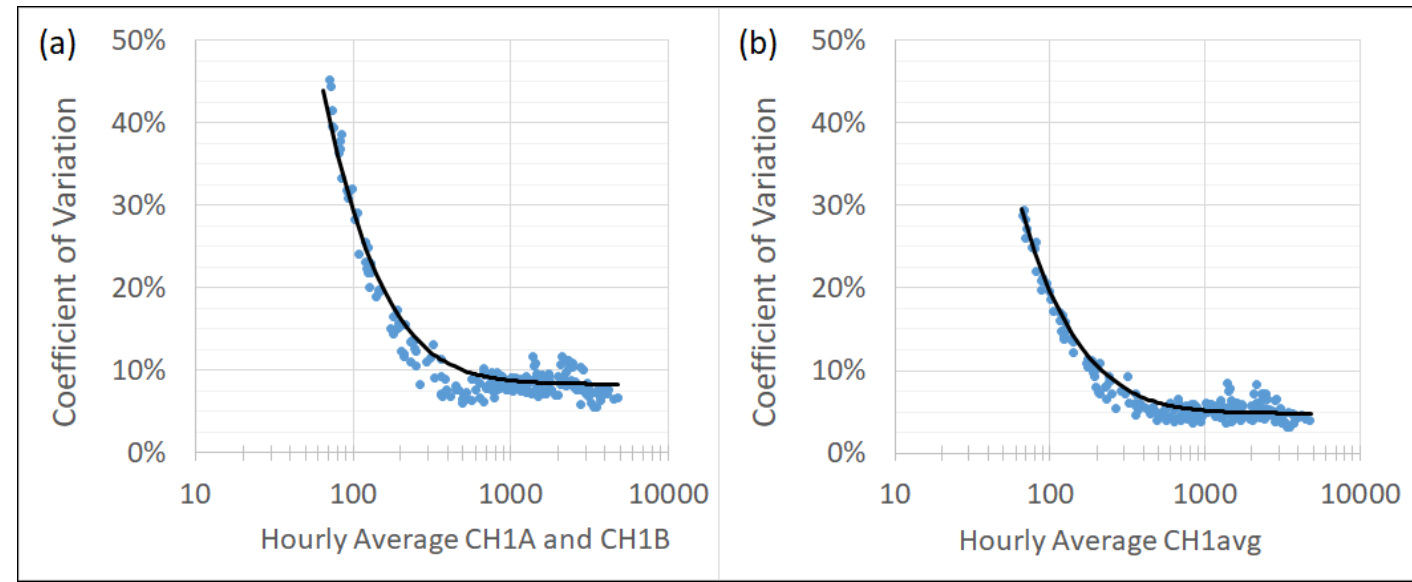

Figure 2. Precision estimated as the coefficient of variation of the hourly CH1A-CH1B (a) and CH1avg values (b) for the 19 collocated sensors and 9 PAs.

The data in Fig. 2 can be modeled by the sum of squares of an additive ( $\left.\mathrm{Un}_{\mathrm{add}}\right)$ and multiplicative

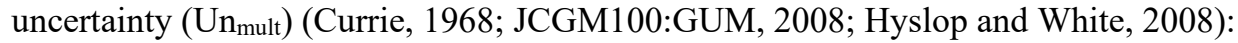

$$
\text { Uncertainty }=\sqrt{U n_{\text {add }}^{2}+U n_{\text {mult }}^{2} * C H 1}
$$

Equation 1 was fitted to the precision data in Fig. 2 where the $\mathrm{Un}_{\text {mult }}$ was set to the average precision at high $\mathrm{CH} 1$ values, and $\mathrm{Un}_{\text {add }}$ was set to 28 and 19 for the $\mathrm{A}$ and $\mathrm{B}$ sensors and $\mathrm{CH} 1$ avg, respectively, to fit the highest variances. The $\mathrm{Un}_{\text {add }}{ }^{2}$ is the variance in CH1 as CH1 approaches zero and is assumed to be equivalent to the uncertainty in values below the instrument minimum detection limit (MDL) or that of blanks (Currie, 1968), which were 0.08 and 0.048 for the A and B sensors and CH1avg, respectively. The coefficient of determination in the model fit for both sets of data was $r^{2}=0.96$. Defining the MDL as the $99 \%$ confidence interval of the Un add (Code of Federal Regulations, 40 CFR 136, https://ecfr.io/Title-40/Part136), MDLs for the individual $\mathrm{CH} 1$ sensors and $\mathrm{CH} 1$ avg were 65 and 44, respectively.

As shown in Sect. S3, the $\mathrm{Un}_{\text {mult }}$ and $\mathrm{Un}_{\text {add }}$ are highly dependent on the systematic biases between the individual $\mathrm{CH} 1$ sensors and $\mathrm{CH} 1$ avg and the four $\mathrm{CH} 1$ sensors with data offsets as the $\mathrm{CH} 1$ approaches zero. Removing these four sensors and normalizing the data for each $\mathrm{CH} 1$ sensor by its average reduced the $\mathrm{Un}_{\text {add }}$ and $\mathrm{Un}_{\text {mult }}$ to $9 \%$ and $3 \%$, respectively, for the $\mathrm{CH} 1$ sensors and $6 \%$ and $1.9 \%$, respectively, for the $\mathrm{CH} 1$ avg data. These results correspond to an MDL of 21 and 14 for the normalized $\mathrm{CH} 1$ sensor and CH1 avg data, respectively. Based on these results, an "off the shelf" PA will have a CH1avg MDL of about 44 and precision of less 


\subsection{Overview of cell-direct and cell-reciprocal nephelometers}

The integrating nephelometer was invented during World War II (Beuttell and Brewer, 1949). It provides a direct measure of aerosol light scattering integrated over a large angular range, the "aerosol light scattering coefficient". This measure requires no assumptions about aerosol composition, size distribution, refractive index, or shape. The most common nephelometer configurations are the "cell-direct" and "cell-reciprocal". Figure 3 presents schematics of the two types of nephelometers. The geometrical relationship between the laser and the photodetector in the PMS resembles a cell-reciprocal nephelometer (Fig. 3b).
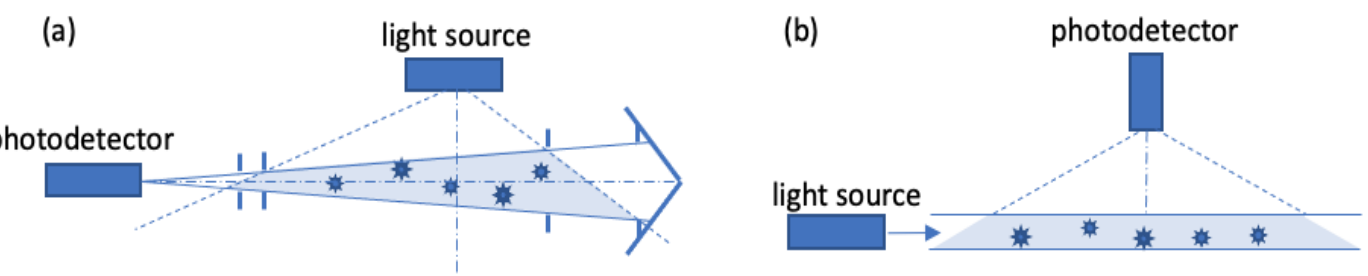

Figure 3. Diagrams of the (a) cell-direct nephelometer and (b) cell-reciprocal nephelometer, simplified from Peñaloza-Murillo (1999).

Middleton (1952) was the first to show that the cell-direct nephelometer with a Lambertian (cosine-adjusted diffuser) light source directly measures the aerosol light scattering coefficient. Anderson et al. (1996), following the derivation in Butcher and Charlson (1972), added geometrical diagrams to make Middleton's derivation much clearer. Mulholland and Bryner (1994) proved that the cell-reciprocal nephelometer with a Lambertian diffuser followed by a photodiode placed at the center of the cell-reciprocal nephelometer also directly measures the aerosol scattering coefficient. This put both the cell-direct and cell-reciprocal nephelometers on equal theoretical footing.

There are a number of cell-direct nephelometers in use today. They include the TSI 3563 (St. Paul, MN, USA; Anderson et al., 1996), the Ecotech Aurora Models 3000 and 4000 (Knoxfield, Australia; Müller et al., 2011), the Radiance Research M903 (Seattle, WA, USA; Heintzenberg et al., 2006), and the Optec NG-2 (Lowell, MI, USA; Molenar, 1997). In contrast, cellreciprocal nephelometers have more limited commercial availability. The photoacoustic extinctiometer (PAX; Droplet Measurement Technologies, Inc., Longmont, CO, USA) and the three-wavelength photoacoustic soot spectrometer (PASS-3) use a cell-reciprocal nephelometer to measure aerosol light scattering coefficient (Arnott et al., 2006). A cosine corrector followed by a photomultiplier tube is placed at the center of the cell-reciprocal nephelometer (AbuRahmah et al., 2006; Nakayama et al., 2015).

A "perfect nephelometer" is one in which the nephelometer is able to see the scattered light over the entire angular range from 0 to 180 degrees. In practice, this cannot be achieved for the celldirect and cell-reciprocal nephelometers. Both the forward and backward scattering angles are truncated. For example, the TSI 3563 nephelometer has measured angular truncation below about 7 degrees in the forward direction and above 170 degrees in the backward direction (Anderson et al., 1996; Heintzenberg and Charlson, 1996). For the PASS-3, Nakayama et al. (2015) found that both the large effective truncation angle (21 degrees) as well as the 
perpendicular polarization of the $532 \mathrm{~nm}$ laser relative to the scattering plane contribute to the large particle size dependence of measured scattering. Light scattering from ammonium sulfate particles of $0.71 \mu \mathrm{m}$ diameter was truncated $50 \%$. Truncation generally results in nephelometers underestimating the contribution of particles larger than approximately $1 \mu \mathrm{m}$ diameter to the scattering coefficient, although corrections have been developed to account for angular nonidealities (e.g., Anderson and Ogren, 1998; Müller et al., 2011).

\section{A physical-optical model of the PMS5003}

To gain insight into how the PMS responds to ambient aerosol properties, a model was developed to estimate the intensity of scattered light impinging on the PMS photodiode. The primary purpose of the model was to predict how the PMS performance compares to other instruments designed to measure the aerosol scattering coefficient, such as integrating nephelometers. The model makes simplifying assumptions about the laser that allow the application of Mie theory to the light scattered from particles in the laser. Details of the model are presented in the Appendix.

The equation describing the intensity of light scattered from a particle in the laser is (Middleton,

where $\mathrm{I}(\theta)$ is the intensity of light at angle $\theta$ scattered from a particle in the volume element $\mathrm{dv}$ (with units of $\left.\mathrm{W} \mathrm{sr}{ }^{-1}\right) ; \beta_{\mathrm{p}}(\theta)$ is the volume scattering function $\left(\mathrm{m}^{-1} \mathrm{sr}^{-1}\right) ; \mathrm{F}_{\mathrm{dv}}$ is the incident laser flux density $\left(\mathrm{W} \mathrm{m}^{-2}\right)$ impinging on the volume element $\mathrm{dv}$; and $\mathrm{dv}$ is the volume element within the laser.

The volume scattering function for a single particle in the laser beam is a function of aerosol diameter $D_{p}$, complex refractive index $m$, laser wavelength $\lambda$, and scattering angle $\theta$ :

where $\left|S_{1}\left(m, \lambda, \theta, D_{p}\right)\right|^{2}$ is the Mie scattering intensity function for laser light polarized parallel to 412 the photodiode surface and perpendicular to the plane of incidence (Bohren and Huffman, 1983).

413 The scattered light intensity from a single particle in the laser beam to a narrow strip across the 414 middle of the photodiode and from all positions in the scattering volume is integrated to predict the total power received by the photodiode as a function of particle diameter $\mathrm{D}_{\mathrm{p}}$ and refractive index m:

$\mathrm{P}\left(\mathrm{m}, \mathrm{D}_{\mathrm{p}}\right)=\mathrm{K} \int_{x=0}^{x=10 \mathrm{~mm}} \int_{\theta 1(x)}^{\theta 2(x)}\left|\mathrm{S}_{1}\left(\mathrm{~m}, \theta, \mathrm{D}_{\mathrm{p}}\right)\right|^{2} \sin (\theta) \mathrm{d} \theta \mathrm{dx}$.

418 Due to the PMS geometry, the upper and lower angular scattering limits for $\theta$ depend on the 419 location, $\mathrm{x}$, of a particle in the laser. Details are provided in the Appendix. This approach can be 420 used to estimate the amount of scattered energy detected from mixtures of particles of varying 421 diameters and indices of refraction, as shown in Eq. (5) 


\section{$423 \quad 3.1$ Model predictions - Deviation from a perfect cosine response}

424 As discussed above, the PMS has a photodetector that is about $1.8 \mathrm{~mm}$ below the laser, resulting in forward scattering and backscattering truncation angles of 18 and 166 degrees, respectively. Furthermore, the photodetector is recessed $0.46 \mathrm{~mm}$ below the scattering chamber base. Equation 4 is used to explore the deviation from a perfect cosine response resulting from the truncated scattering volume and recessed detector. It is shown in Fig. 4. For these calculations, $\mathrm{S}_{1}\left(\mathrm{~m}, \theta, \mathrm{D}_{\mathrm{p}}\right)$ is set equal to 1 , which corresponds to isotropic scattering or a volume scattering function that is constant over all scattering angles. It is assumed that the detector has a Lambertian response, i.e., the light detected is independent of the direction of the incident energy, which results in a detector cosine response. Figure 4 shows a perfect cosine response in yellow, while the red line shows the deviation from a perfect cosine response due to angular $0.46 \mathrm{~mm}$ below the chamber base. All curves have been normalized to one at 90 degrees.

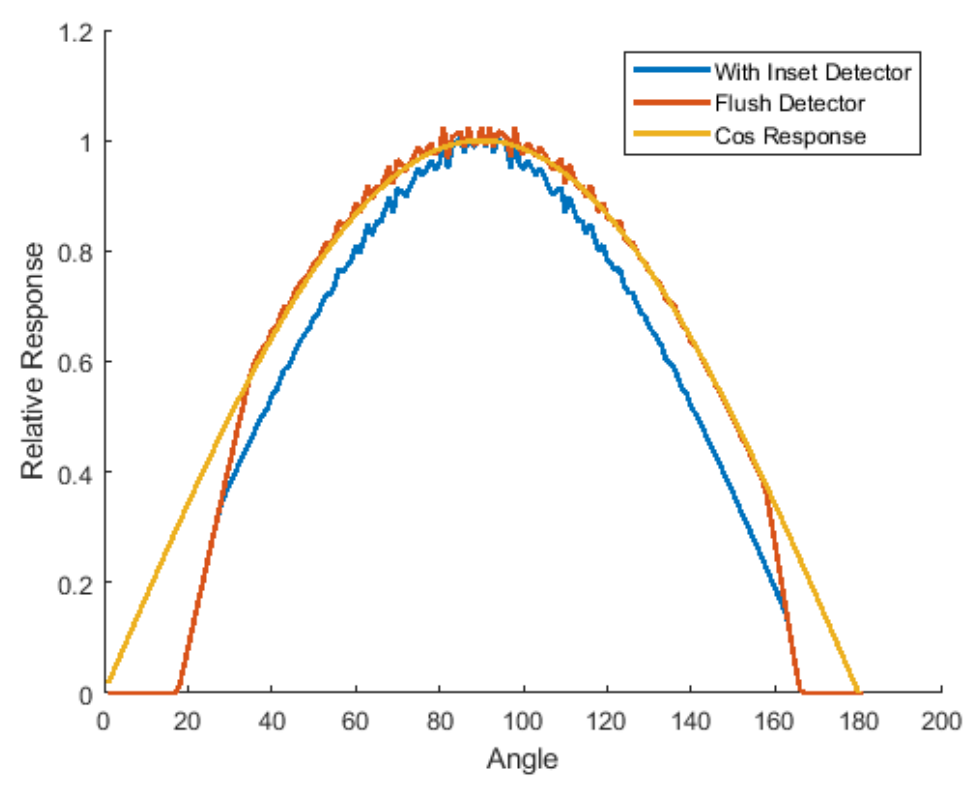

Figure 4. Relative response of the photodetector resulting from truncated scattering angles and a recessed photodetector. See explanation of the different curves in text.

\section{$438 \quad 3.2$ Model predictions - Intensity versus position on the detector}

439 Figure 5 provides an example of the energy distribution on the photodiode as a function of 440 position in the laser and on the diode resulting from scattering from particles represented by a 441 lognormally distributed aerosol volume size distribution with a volume mean diameter of 0.33 $442 \mu \mathrm{m}$ and geometric standard deviation of 1.7. Figure 5 shows model predictions of the relative 

detector.

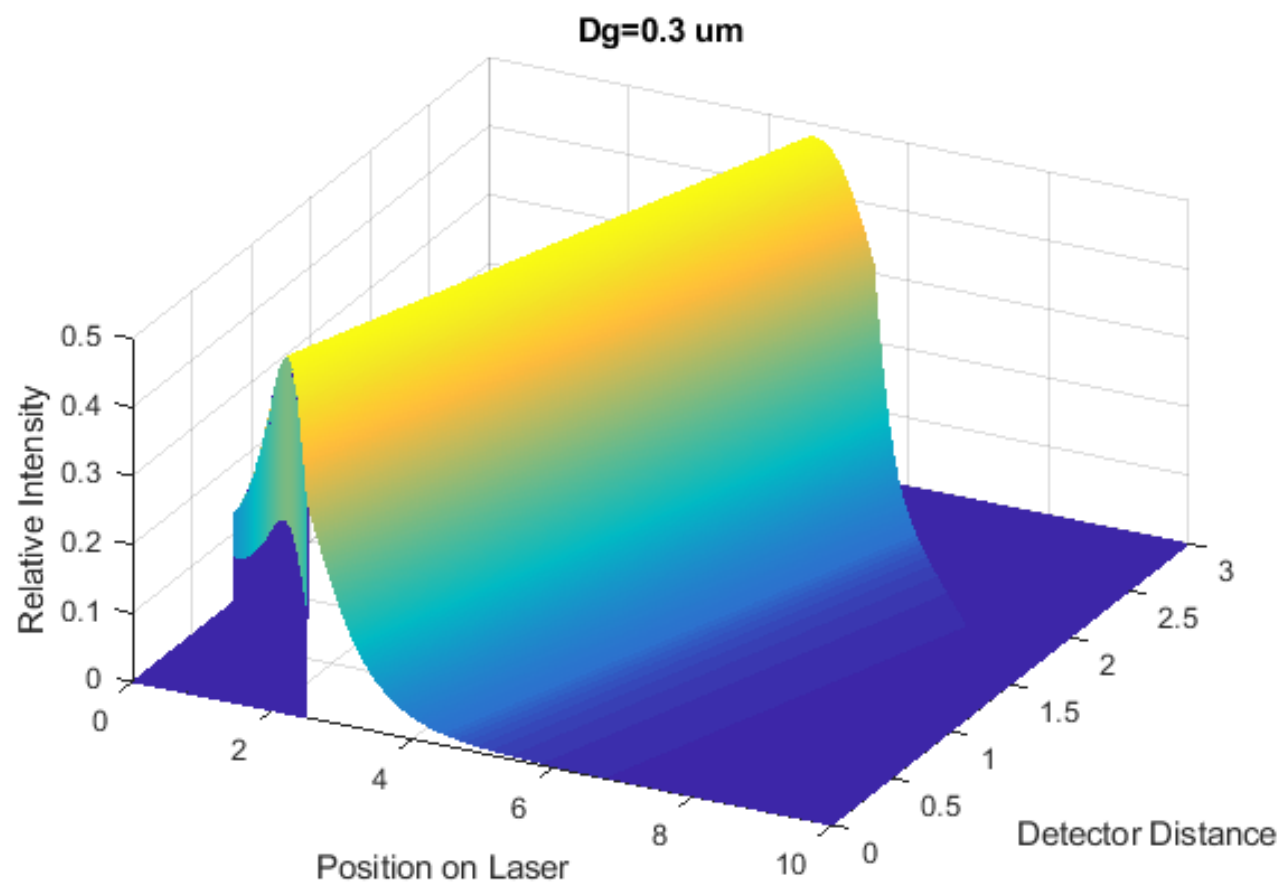

Figure 5. Relative intensity of radiant energy scattered by a lognormally distributed aerosol volume size distribution with a volume mean diameter of $0.33 \mu \mathrm{m}$ and geometric standard deviation of 1.7 as a function of location of scattering event in the laser and as a function of position on the photodiode. Assumed laser wavelength was $650 \mathrm{~nm}$, and the particle index of refraction was assumed to be 1.53. Positions in the laser and detector are from left to right as in Fig. 1.

The masking resulting from a recessed detector truncates the scattering both in the most forward and backward scattering angles. This masking is shown as the triangular area corresponding to distance down the laser and detector of $0.0-2.5 \mathrm{~mm}$ and $0.0-0.78 \mathrm{~mm}$, respectively, for the forward scattering angles and 5.6-10 $\mathrm{mm}$ and $1.44-3.0 \mathrm{~mm}$, respectively, for backscattering. Because the laser is parallel to the photodetector, which is assumed to have a $\cos (90-\theta)$ response, the maximum energy scattered to the detector is approximately at $\theta=90$ degrees. However, more energy is scattered to the detector for scattering angles less than 90 degrees, which corresponds to forward scattering, and very little energy is detected by the photodiode for particles in the laser that are greater than about $8 \mathrm{~mm}$ down the laser beam, even though the detector is exposed to particles in the laser that are $10 \mathrm{~mm}$ away from the laser exit hole. These distances down the laser correspond to backscattering. The total energy detected by the photodiode is the sum or integral across both the detector surface and position in the laser and corresponds to the volume under the curve depicted in Fig. 5. 


\subsection{Model predictions - Predicted photodiode response as a function of particle diameter}

The PMS differs from a perfect nephelometer in at least five important ways:

1. The laser is polarized, whereas the nephelometer light source is unpolarized.

2. The laser beam profile is not a simple plane wave, but complex in shape. The laser beam profile evolves significantly as it is focused over the photodiode.

3. The photodiode likely does not have a perfect cosine response.

4. The PMS geometry limits the photodiode to receiving scattered light between approximately 18 and 166 degrees, whereas a perfect nephelometer measures all energy scattered between 0 and 180 degrees.

5. The unknown PMS signal processing removes the light scattering signal from $\mathrm{CO}_{2}$, Suva, and filtered air. These gases are used to calibrate nephelometers, but cannot be used to calibrate the PMS.

The effects of these differences can be seen in Fig. 6, which shows predicted photodiode response as a function of particle diameter. The perfect nephelometer response is in blue, and the PMS response is in yellow. The red line predicts PMS response if the laser were not polarized. Relative intensities have been normalized to an ideal nephelometer measurement of a $0.1 \mu \mathrm{m}$ diameter particle, which is akin to adjusting the laser power such that the scattered power at a diameter equal to $0.1 \mu \mathrm{m}$ is the same for all configurations. Scattering as a function of particle diameter is nearly the same for all three configurations from $0.1 \mu \mathrm{m}$ to about $0.3 \mu \mathrm{m}$. At about 0.8 to $1.0 \mu \mathrm{m}$, the response of a PMS with an unpolarized laser is about half that of an ideal nephelometer, and the use of a polarized laser reduces its response to about $30 \%$ to that of an ideal nephelometer. For particles above $2 \mu \mathrm{m}$ in diameter, the PMS response compared to an ideal nephelometer is decreased by about 75\%. Additionally, the PMS manual (Zhou, 2016) quotes a lower detection limit diameter of $0.3 \mu \mathrm{m}$. The model predicts that particles smaller than $0.3 \mu \mathrm{m}$ in diameter would be detected by the PMS, in direct proportion to their contribution to the scattering coefficient.

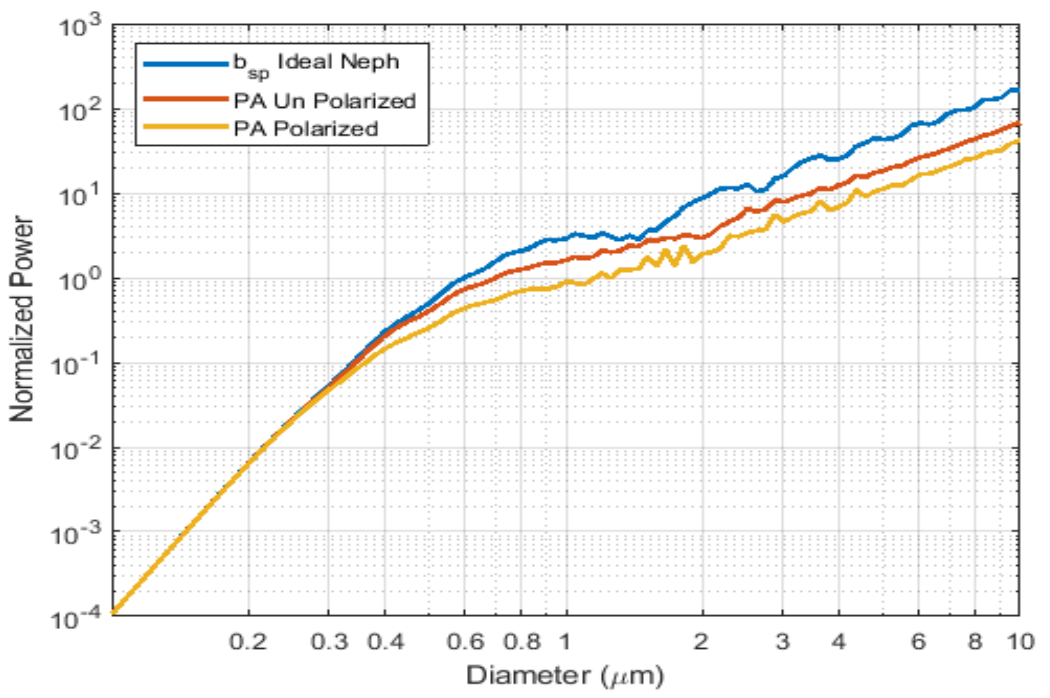


Figure 6. Normalized power detected by an ideal integrating nephelometer, a PMS with an unpolarized light source, and a PMS with a perpendicularly polarized light source plotted as a function of particle diameter. Modeled light source wavelength is $657 \mathrm{~nm}$, and the particle index of refraction is 1.55 . See explanation of the different curves in text.

These differences in geometry and optics from an ideal nephelometer are further highlighted in Fig. 7. To highlight the effect of polarization, the blue line shows the ratio of an ideal nephelometer with a laser light source that is perpendicularly polarized to an ideal nephelometer with an unpolarized light source. The red line shows the effects that polarization and PMS geometry have on the measured scattering signal. Again, all hypothetical instrument responses have been normalized to a particle diameter of $0.1 \mu \mathrm{m}$. Relative to scattering for a $0.1 \mu \mathrm{m}$ particle, the polarization alone reduces the scattering signal of an ideal nephelometer by $40 \%$ for particles with diameters in the $0.8-1.5 \mu \mathrm{m}$ size range. The additional effect of PMS scattering geometry reduces the scattering signal at $0.8-1.0 \mu \mathrm{m}$ by about another $30 \%$ relative to an ideal nephelometer.

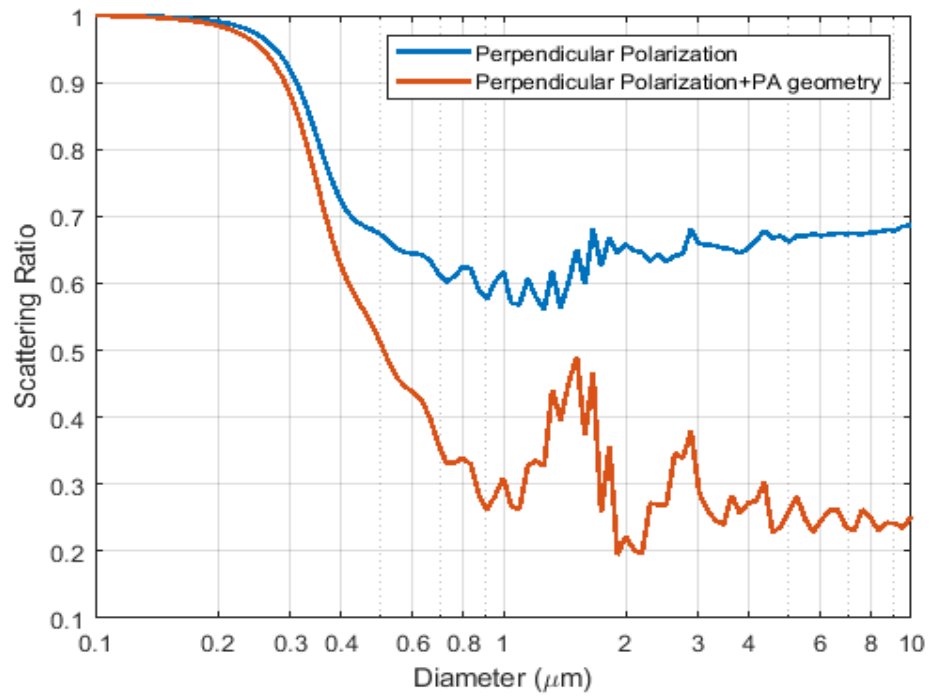

Figure 7. Ratio of scattering of a "perfect" nephelometer to a nephelometer with a light source that is perpendicularly polarized (blue) and to a perpendicularly polarized nephelometer with PMS geometry (red) as a function of particle diameter.

\subsection{Model predictions - Differentiating by particle size}

The irradiance received by the PMS photodiode from a particle of a given diameter and refractive index depends on the particle's location in the laser beam. The model predicts that particles of different sizes may contribute the same irradiance to the photodiode, depending on their location in the beam, or conversely, light scattered by a particle of a given size can vary by more than an order of magnitude.

As an example, the model predicts that all of the particles in Fig. 8 contribute the same irradiance to the PMS photodiode. The smaller particles contribute the same irradiance by scattering in the 
more effective forward scattering regime. The larger particles contribute the same irradiance by scattering in the less effective backscattering regime. The photodiode and its associated electronics would not be able to differentiate between them. As a result, the model predicts that the values reported in the six PA-PMS particle size channels from $>0.3 \mu \mathrm{m}$ to $>10 \mu \mathrm{m}$ cannot correctly represent the aerosol size distribution.

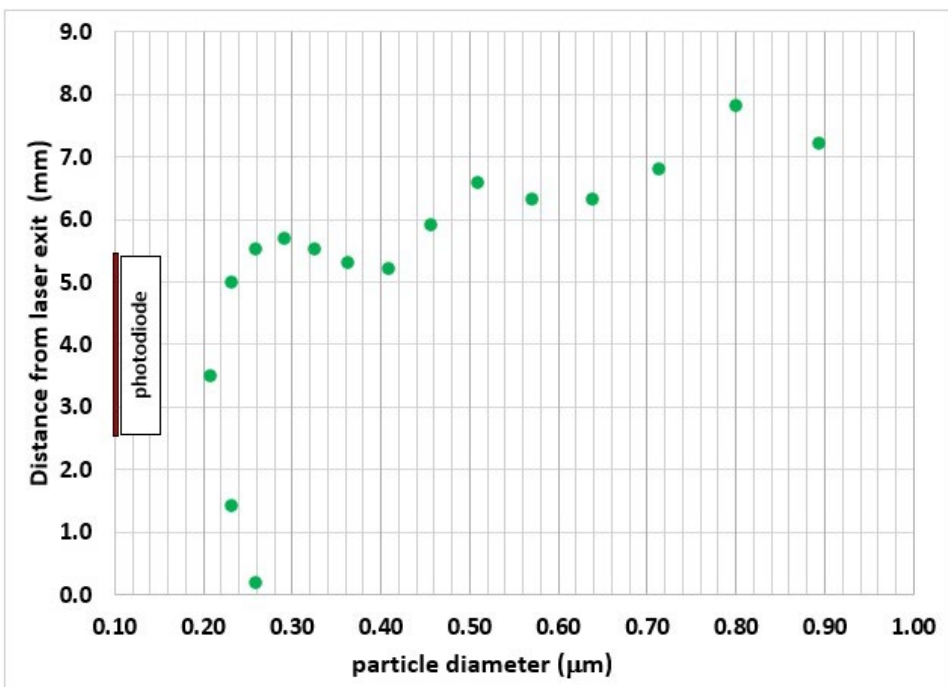

Figure 8. The model predicts that different size particles can generate the same irradiance on the photodiode, depending on their location in the laser beam. In this example, each of the particles would create $1.7 \times 10^{-2}$ picowatts of scattered irradiance on the photodiode.

\section{Experimental - Field studies}

Field experiments were conducted at two of the NFAN aerosol monitoring stations: the Mauna Loa Baseline Observatory in Hawaii and the Table Mountain Test Facility in Colorado. Both sites have large suites of aerosol instrumentation and daily access for scientists and technicians to inspect, calibrate, and maintain the instruments. These sites also have integrating nephelometers (TSI 3563, St. Paul, MN, USA) against which to evaluate the PA monitors.

\subsection{Description of Mauna Loa site}

The Mauna Loa Baseline Observatory (MLO) is located on the north flank of the Mauna Loa volcano, on the Big Island of Hawaii $\left(19.536^{\circ} \mathrm{N}, 155.576^{\circ} \mathrm{W}, 3397 \mathrm{~m}\right.$ asl). The observatory is a premier atmospheric research facility that has been continuously monitoring and collecting data on global background conditions and atmospheric change since the 1950s (https://www.esrl.noaa.gov/gmd/obop/mlo/). Continuous aerosol measurements at MLO began in the mid-1970s with the installation of condensation particle counters and an integrating nephelometer (Bodhaine and Mendonca, 1974; Bodhaine et al., 1981). MLO lies above the strong marine temperature inversion layer present in the region, which separates the morepolluted lower portions of the island atmosphere in the marine boundary layer from the much cleaner free troposphere. MLO experiences a diurnal wind pattern (Ryan, 1997) that is strongly influenced by the daily heating and nighttime cooling of the dark volcanic lava rock that makes 
up the mountain. This "radiation wind" brings air up from lower elevations during the daytime, when atmospheric measurements reflect the local mountain environment. In contrast, during the nighttime, downslope winds develop, and the measurements at MLO are typically dominated by clean, free-tropospheric conditions (Chambers et al., 2013). At these times, the aerosol measurements at MLO often reflect some of the cleanest conditions at any station in the northern hemisphere. It has long been known, however, that episodic long-range transport of Asian pollution and dust aerosols occurs, most frequently in the springtime (Shaw, 1980; Miller, 1981; Harris and Kahl, 1990), and these aerosol events can influence both the daytime and nighttime measurements at MLO. Consequently, the aerosol levels at MLO vary over a large range, from extremely low to at times mildly elevated. Here we use observations from the MLO integrating nephelometer to evaluate the PMS sensor.

\subsection{Description of Boulder Table Mountain site}

The Table Mountain Test Facility (BOS) is a large restricted-access federal complex located 14 $\mathrm{km}$ north of Boulder, Colorado $\left(40.125^{\circ} \mathrm{N}, 105.237^{\circ} \mathrm{W}, 1689 \mathrm{~m}\right.$ asl $)$. NOAA conducts atmospheric research at this site, and in addition to its NFAN station, it is one of the Global Monitoring Laboratory's seven U.S. Surface Radiation Network (SURFRAD) sites (https://www.esrl.noaa.gov/gmd/grad/surfrad/tablemt.html). Many instruments for measuring surface and column aerosol properties are maintained at this location and used for long-term monitoring of the atmosphere.

The BOS site lies just east of the Front Range foothills of the Rocky Mountains and is typical of a semi-arid, high plains environment. It is a high mesa of predominantly grassland with some desert scrub vegetation. The location is well suited for sampling of wildfire smoke plumes during fire season in the western United States (summer and autumn), dust events at any time of the year, and occasional urban pollution episodes. The NFAN station at BOS (https://www.esrl.noaa.gov/gmd/aero/net/bos.html) was completed in September 2019. BOS operates an integrating nephelometer and a differential mobility particle spectrometer (DMPS). Both provided useful data for evaluating some of the predictions from the physical-optical model we developed for the PMS sensor.

\section{$573 \quad 4.3$ PA monitors}

PA-PMS monitors were installed on the aerosol towers at the MLO and BOS stations, just below the main aerosol inlets. MLO had two PA-PMS monitors, one gently heated and one unheated, whereas BOS had one gently heated PA-PMS monitor. Prior to deployment, the monitors were tested in a filtered air chamber for 4 hours to ensure that the 1 -h average $\mathrm{CH} 1$ values were less than 1 when no particles were present. One of the PMS sensors in the unheated MLO PA had 1-h average $\mathrm{CH} 1$ values of 27 when no particles were present. The heated monitors were wrapped with heating tape and powered by small DC power supplies. All the monitors were covered with stainless steel flashing $5 \mathrm{~cm}$ below the bottom to prevent rain and snow from entering the inlet (Fig. S13).

583 The PA-PMS monitors were warmed in an effort to reduce the sample relative humidity (RH) to 584 be closer to that of the nephelometer, which is unavoidably heated by the warmth of the 585 laboratory and by the nephelometer's halogen lamp to above ambient temperatures. Because of 586 this warming, the RH inside the nephelometers rarely exceeded 40\%. Both MLO and BOS are 
low-RH environments under normal conditions, although occasionally moist air masses are encountered. The heating of the monitors increased the sample temperatures by 5-8 C, which helped to lower the sample RH. While the PA heating was not controlled to achieve an RH match with the nephelometer, it brought the sample RH of the two measurements closer together.

Due to internet protocols at both sites, PA's wireless data transmission feature was not used, and the data were stored on the internal micro-SD card. At approximately 1 month intervals, the data were downloaded from the micro-SD cards, and the PAs were returned to service. Outputs from the two PMS sensors were then compared at these intervals to determine if the PAs were still functioning properly. In this study, the $80 \mathrm{~s}$ or 2 min averages were used to create $1 \mathrm{~h}$ averages to compare the PA observations to those of the nephelometer and the DMPS.

\subsection{Integrating nephelometer}

The integrating nephelometer (TSI Inc., model 3563) measures the aerosol light scattering coefficient at three wavelengths $(450,550$, and $700 \mathrm{~nm})$. At both sites, the sample flow path is switched every 6 minutes between 1 and $10 \mu \mathrm{m}$ aerodynamic diameter, multijet, Berner-type impactors. Here, the scattering coefficients at $550 \mathrm{~nm}$ for both the PM1 and PM10 size fractions are used for comparison with the PMS measurements. These are referred to as $b_{s p 1}$ and $b_{s p 10}$, respectively.

There are two quality checks of the nephelometer operation made in the field. First, the nephelometer automatically samples filtered air once per hour. This provides a record of the stability of the instrument background measurement. Second, the nephelometer calibration is manually checked on a monthly basis using $\mathrm{CO}_{2}$ and filtered air (Anderson et al., 1996). The $1 \mathrm{~h}$ average $b_{\text {sp } 1}$ in filtered air is $0.01 \mathrm{Mm}^{-1}$ with a standard deviation of $0.12 \mathrm{Mm}^{-1}$, based on 125 hours of sampling filtered air.

The nephelometer measurements were corrected for angular truncation (Anderson and Ogren, 1998) and reported at STP. Weekly data review provides quality assurance of the nephelometer data. Scattering coefficient data were averaged to $1 \mathrm{~min}$ resolution for logging and were further averaged to hourly resolution for comparison with the PA data. The $1 \mathrm{~h}$ average $\mathrm{b}_{\mathrm{sp} 1}$ uncertainties of the nephelometer measurements are $\sim 0.13 \mathrm{Mm}^{-1}$ for scattering coefficients less than $1.0 \mathrm{Mm}^{-1}$ and $\sim 10 \%$ for scattering coefficients greater than $1 \mathrm{Mm}^{-1}$ (Sherman et al., 2015).

\subsection{Differential mobility particle spectrometer (DMPS)}

The DMPS was provided by the Institute for Atmospheric and Earth System Research, University of Helsinki, Finland. It was checked and calibrated by the World Calibration Centre for Aerosol Physics (WCCAP) at Leibniz Institute for Tropospheric Research (IfT), Leipzig, Germany, just prior to deployment at NOAA's Table Mountain site. After shipment from IfT to NOAA, the DMPS was again checked by aerosolizing polystyrene latex spheres and confirming that the peaks occurred in the correct size bins. The DMPS was housed inside the same building as the nephelometer at BOS and sampled aerosols through the same inlet, although the DMPS flow did not pass through the aerosol impactors.

The DMPS provides 40 channels of particle concentration versus size, ranging from mobility diameters of $0.01 \mu \mathrm{m}$ to $0.8 \mu \mathrm{m}$. The $0.1 \mu \mathrm{m}$ to $0.8 \mu \mathrm{m}$ channels of the DMPS were used to 
calculate hourly-average fine aerosol scattering coefficient distributions and the total fine aerosol scattering coefficient. The hourly-average, DMPS-calculated fine aerosol scattering coefficients were compared to the nephelometer-measured fine aerosol scattering coefficients to check operational consistency (Fig. S14). No operational changes were made to the DMPS during this field study. This study did not measure coarse aerosol size distributions. The DMPS hourlyaverage fine aerosol scattering coefficient distributions were used with the PMS physical-optical model to predict total $1 \mathrm{~h}$ average scattered irradiance on the photodiode.

\section{4}

635

636

637

638

639

640

641

642

\section{3}

644

645

646

647

648

\section{Results}

This section describes our evaluation of the PA-PMS using field data from MLO and BOS. First, we provide an overview of the observational data. We then assess how well the model described in Sect. 3 is able to represent the observed data and show consistency with results previously reported in the literature. Next, we present results showing the potential of the PA-PMS to perform as a nephelometer. Finally, we note how the size information output by the PA is not correct due to the PA's primary measurement being a scattering measurement. For the results presented below, data from the PA-PMS, nephelometer and DMPS were averaged to hourly frequency and merged prior to analysis.

\subsection{Field data overview}

Heated PA monitors were deployed at the MLO and BOS observatories for 15 and 11 months, respectively (Table 1). At both sites weather had no impact on the operation of the PA instrument, and downtime only occurred during data downloading.

Table 1. Summary of PA, TSI nephelometer, and DMPS data coverage.

\begin{tabular}{|c|c|c|c|c|c|c|c|c|}
\hline & \multicolumn{4}{|c|}{ number of hours } & \multicolumn{3}{c|}{ percent coverage } & \\
\hline site & PA-PMS & TSI neph & DMPS & overlap & PA-PMS & TSI neph & DMPS & Time period \\
\hline MLO & 9371 & 9204 & na & 9204 & 97.6 & 95.9 & na & $\begin{array}{c}\text { 6 May 2019 to 5 June } \\
2020\end{array}$ \\
\hline BOS & 7716 & 7479 & 7045 & 6901 & 97.7 & 94.7 & 89.2 & $\begin{array}{c}13 \text { February } 2020 \text { to } 6 \\
\text { January 2021 }\end{array}$ \\
\hline
\end{tabular}

These two deployments provide an excellent dataset for assessing PA performance in both a clean location (MLO) and in an environment with more elevated particle concentration (BOS). As shown in Table 2, during the field study at MLO, the median CH1 was 26.7. The median $b_{\mathrm{sp} 1}$ was $0.76 \mathrm{Mm}^{-1}$ at $550 \mathrm{~nm}$ which is approximately $10 \%$ of Rayleigh scattering at the MLO altitude. The reported PM2.5 mass concentration from the PA was zero for most of the MLO deployment. The $\mathrm{CH} 1$ and $\mathrm{b}_{\mathrm{sp} 1}$ are adjusted to STP in Table 2 . The air quality at BOS was less pristine than at MLO and is more representative of nonurban continental air quality. The very high maximum $\mathrm{CH} 1$ and $\mathrm{b}_{\mathrm{sp} 1}$ at BOS reported in Table 2 occurred during smoke events in the summer and autumn of 2020. One of the BOS PMS sensors experienced approximately $10 \%$ degradation in sensitivity after one year in the field (Fig. S15). 
Table 2. Summary of PA-PMS and nephelometer hourly observations at MLO and BOS.

661

662

663

664

665

666

667

668

669

\begin{tabular}{|c|c|c|c|c|c|c|c|c|}
\hline & \multicolumn{3}{|c|}{ 1h median (average) } & \multicolumn{3}{c|}{ 1h Range min-max } \\
\hline & \multicolumn{2}{|c|}{ PA-PMS } & \multicolumn{2}{|c|}{ TSI nephelometer } & \multicolumn{2}{c|}{ PA-PMS } & \multicolumn{2}{c|}{ TSI nephelometer } \\
\hline Site & $\begin{array}{c}\mathrm{PM} 2.5 \\
\mu \mathrm{g} \mathrm{m}^{-3}\end{array}$ & $\mathrm{CH} 1$ & $\begin{array}{c}\mathrm{b}_{\text {sp } 10} \\
\mathrm{Mm}^{-1}\end{array}$ & $\begin{array}{c}\mathrm{b}_{\mathrm{sp} 1} \\
\mathrm{Mm}^{-1}\end{array}$ & $\begin{array}{c}\mathrm{PM} 2.5 \\
\mu \mathrm{g} \mathrm{m}^{-3}\end{array}$ & $\mathrm{CH} 1$ & $\begin{array}{c}\mathrm{b}_{\text {sp } 10} \\
\mathrm{Mm}^{-1}\end{array}$ & $\begin{array}{c}\mathrm{b}_{\text {sp } 1} \\
\mathrm{Mm}^{-1}\end{array}$ \\
\hline MLO & $\begin{array}{c}0.000 \\
(0.12)\end{array}$ & $\begin{array}{c}26.7 \\
(75.2)\end{array}$ & $\begin{array}{c}1.19 \\
(2.82)\end{array}$ & $\begin{array}{c}0.76 \\
(1.50)\end{array}$ & $0.0-21.6$ & $\begin{array}{c}0.26- \\
1649\end{array}$ & $\begin{array}{c}-0.35- \\
35.2\end{array}$ & $-0.29-34.2$ \\
\hline BOS & $\begin{array}{c}3.37 \\
(8.42)\end{array}$ & $\begin{array}{c}720 \\
(1422)\end{array}$ & $\begin{array}{c}14.6 \\
(32.4)\end{array}$ & $\begin{array}{c}9.9 \\
(20.9)\end{array}$ & $0.0-571$ & $\begin{array}{c}7.38- \\
63340\end{array}$ & $\begin{array}{c}-0.11- \\
4097\end{array}$ & $\begin{array}{c}-0.44- \\
2596\end{array}$ \\
\hline
\end{tabular}

\subsection{Relationship between model predictions and field data}

The PMS sensor is described by the manufacturer as a particle counter that measures particles between $0.3 \mu \mathrm{m}$ and $10 \mu \mathrm{m}$ in six size bins. Based on the theoretical characterization of the PMS sensor described in Sect. 3, the sensor is more akin to a polarized, reciprocal integrating nephelometer than a particle counter. Below, the field data and theoretical model are used to demonstrate that the raw PMS sensor signal is an integrated scattering measurement that is sensitive to particles smaller than $0.3 \mu \mathrm{m}$ but relatively insensitive to particles larger than 1.0 $\mu \mathrm{m}$.

\subsubsection{Predicted photodiode irradiance versus $\mathrm{CH1}$ field data at BOS}

Our model described in Sect. 3 and the Appendix predicts a value proportional to the scattered irradiance impinging on the PMS photodiode as a function of particle diameter and concentration. This was done using the DMPS size distribution data from BOS. The modeled PMS photodiode output is plotted against the PMS CH1 output (Fig. 9). The predicted photodiode output is linearly correlated $\left(\mathrm{R}^{2}=0.90\right)$ with $\mathrm{CH} 1$ over 4 orders of magnitude. The linear relationship between $\mathrm{CH} 1$ and modeled photodiode response suggests the likelihood that the $\mathrm{CH} 1$ output is directly related to what the photodiode is sensing (i.e., scattering from all particles in the scattering volume). The PA-PMS reported values, such as concentrations of particle numbers in various size ranges or PM concentrations, are quantities derived from the scattering signal and the use of an undescribed algorithm. 


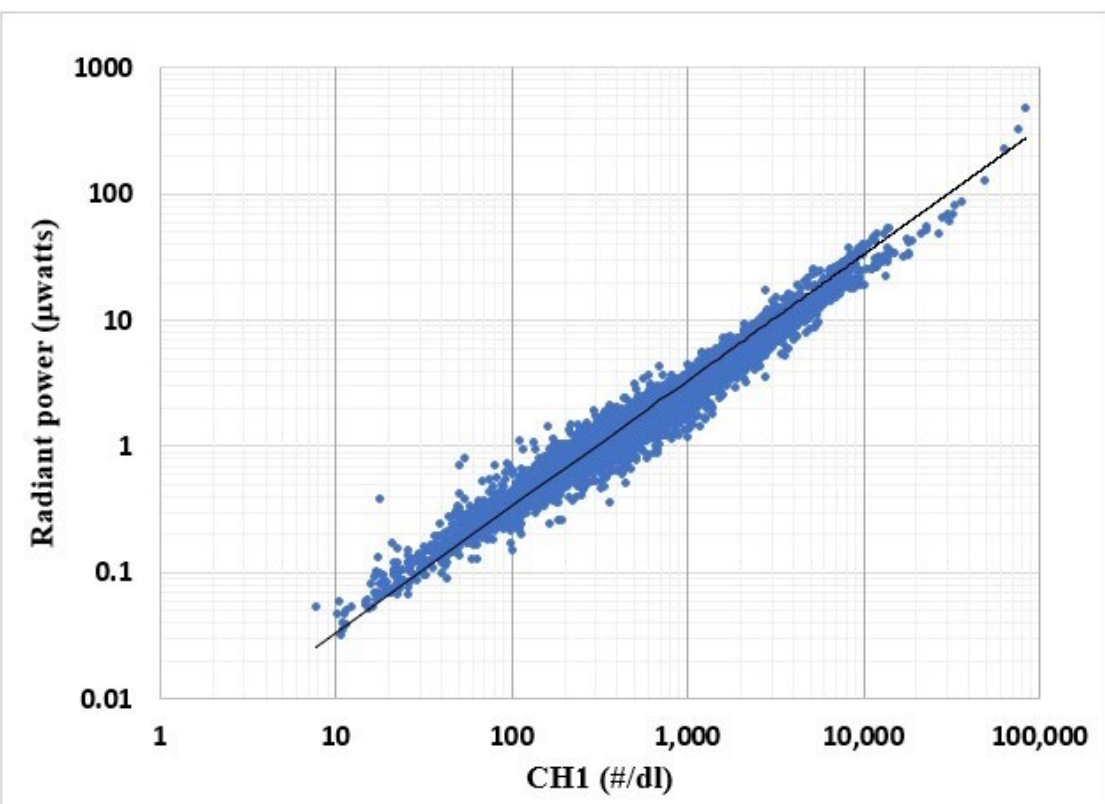

Figure 9. One hour average $\mathrm{CH} 1$ reported values are plotted against model-predicted radiant power (or energy) in $\mu$ watts on the photodiode. Both the CH1 and DMPS data were adjusted to STP conditions. The ordinary least squares regression line is also shown.

\subsubsection{Predicted aerosol size truncation versus field data at BOS}

The PMS physical-optical model described in Sect. 3 predicts that if $\mathrm{CH} 1$ is proportional to the photodiode power, then its signal will be truncated relative to a perfect nephelometer. Thus, the ratio $\mathrm{CH} 1 / \mathrm{b}_{\mathrm{sp} 1}$ should decrease as median scattering diameter increases. To test this prediction, the DMPS data from BOS were used to calculate hourly-average aerosol scattering coefficient distributions for diameters between $0.1 \mu \mathrm{m}$ and $0.8 \mu \mathrm{m}$. A wavelength of $657 \mathrm{~nm}$ and a particle refractive index of $1.53-0.0 \mathrm{i}$ were used for the calculations. The median scattering diameter (MSD) was calculated for each hour. The MSD is the aerosol diameter at which approximately half of the light scattering is due to particles smaller than the MSD and the other half to particles larger than the MSD. The MSD was then compared to the ratio of the measured CH1 and $b_{\text {sp } 1}$ values, i.e., $\mathrm{CH} 1 \mathrm{avg} / \mathrm{b}_{\mathrm{sp} 1}$, for each of these hours. The results shown in Fig. 10 are consistent with the PMS physical-optical model. The highest $\mathrm{CH} 1 \mathrm{avg} / \mathrm{b}_{\mathrm{sp} 1}$ ratios tend to occur for aerosols with the lowest MSD and decrease as MSD increases. The results show, as suggested above, that the PMS can efficiently detect particles below $0.3 \mu \mathrm{m}$ in diameter in proportion to their contribution to the scattering coefficient. 


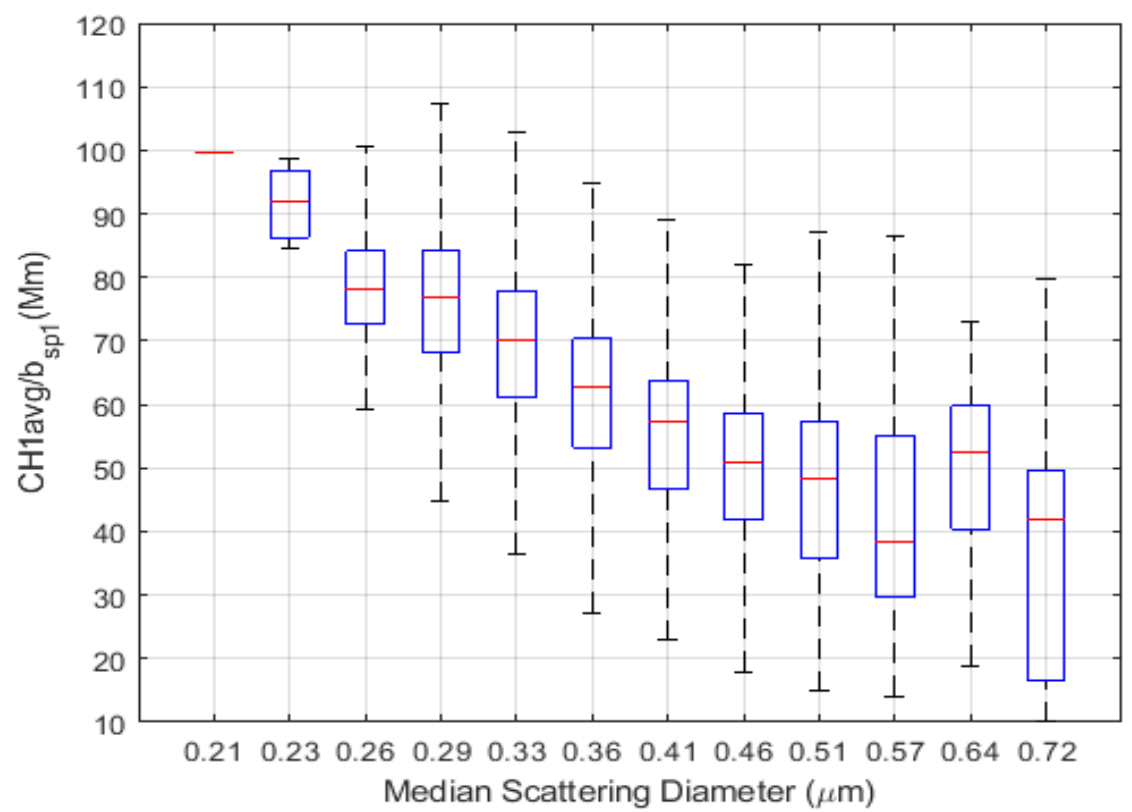

Figure 10. Observed decrease in $\mathrm{CH} 1 \mathrm{avg} / \mathrm{b}_{\mathrm{sp} 1}$ ratio as function of median scattering diameter. Red line is the median value, while the upper and lower edges of the blue box represent the $75^{\text {th }}$ and $25^{\text {th }}$ percentile values, respectively. Whiskers extend to the $9^{\text {th }}$ and $91^{\text {st }}$ percentiles. Overall average $\mathrm{CH} 1 \mathrm{avg} / \mathrm{b}_{\mathrm{sp} 1}$ ratio for all hours is 65 . Data are for 6839 hourly averages at BOS. Approximately $67 \%$ of the MSDs observed at BOS were between $0.29 \mu \mathrm{m}$ and $0.36 \mu \mathrm{m}$, and $98 \%$ of MSDs were between $0.26 \mu \mathrm{m}$ and $0.46 \mu \mathrm{m}$.

\subsubsection{Estimating the scattering coefficient minimum detection limit of the PA-PMS}

The precision analysis in Sect. 2 indicates that the PA monitors used in this study estimated $1 \mathrm{~h}$ average $\mathrm{CH} 1$ and $\mathrm{CH} 1$ avg MDLs of approximately 21 and 14, respectively. The estimated $1 \mathrm{~h}$ average MDL $b_{\text {sp } 1}$ of the TSI 3563 nephelometer is approximately $0.20 \mathrm{Mm}^{-1}$, based on filtered air tests. Further analysis of the relationship between $\mathrm{CH} 1$ and $\mathrm{b}_{\mathrm{sp} 1}$ at low levels was performed by plotting the ratio, $\mathrm{CH} 1 \mathrm{avg} / \mathrm{b}_{\mathrm{sp} 1}$, for the combined MLO and BOS dataset, as a function of $\mathrm{b}_{\mathrm{sp} 1}$. This relationship is shown graphically in Fig. 11. The data values were first averaged over 6 hours because hourly $b_{s p 1}$ values near zero included many small negative $b_{s p 1}$ values due to the very clean conditions occasionally observed at MLO. The averaging eliminated all but five negative $b_{\mathrm{sp} 1}$ values, which were removed from the dataset. The $C H 1 \mathrm{avg} / b_{\mathrm{sp} 1}$ and $b_{\mathrm{sp} 1}$ values were further averaged over six data points after sorting the data on $b_{\text {sp } 1}$ levels to more clearly show the relationship between $\mathrm{CH} 1$ avg and $\mathrm{b}_{\mathrm{sp} 1}$. At $\mathrm{b}_{\mathrm{sp} 1}>5 \mathrm{Mm}^{-1}$, the $\mathrm{CH} 1 \mathrm{avg} / \mathrm{b}_{\mathrm{sp} 1}$ ratio is relatively constant at 67, the yellow line in Fig. 11. The yellow line is the slope of CH1avg versus $b_{\text {sp } 1}$ at $b_{\text {sp } 1}$ values greater than $5 \mathrm{Mm}^{-1}$. The $C H 1$ avg $/ b_{\text {sp } 1}$ ratio systematically decreases from its highest values to about 35 , the slope of $\mathrm{CH} 1$ avg versus $b_{\mathrm{sp} 1}$ at $b_{\mathrm{sp} 1}=0.4 \mathrm{Mm}^{-1}$. For $\mathrm{b}_{\mathrm{sp} 1}$ $<0.4 \mathrm{Mm}^{-1}$ the $\mathrm{CH} 1 \mathrm{avg} / \mathrm{b}_{\mathrm{sp} 1}$ ratio then increases significantly as $\mathrm{b}_{\mathrm{sp} 1}$ decreases, consistent with 

and a CH1avg value of about $14 \pm 5$ is consistent with the estimated CH1avg MDL of 14.

Based on these results, the $1 \mathrm{~h}$ average $\mathrm{CH} 1$ sensor MDL for hourly data in units of scattering is approximately $0.4 \mathrm{Mm}^{-1}$ at MLO. Laboratory tests challenging the PAs with known low-level, spiked aerosol concentrations and defined size distributions are needed to further refine the estimated MDL.

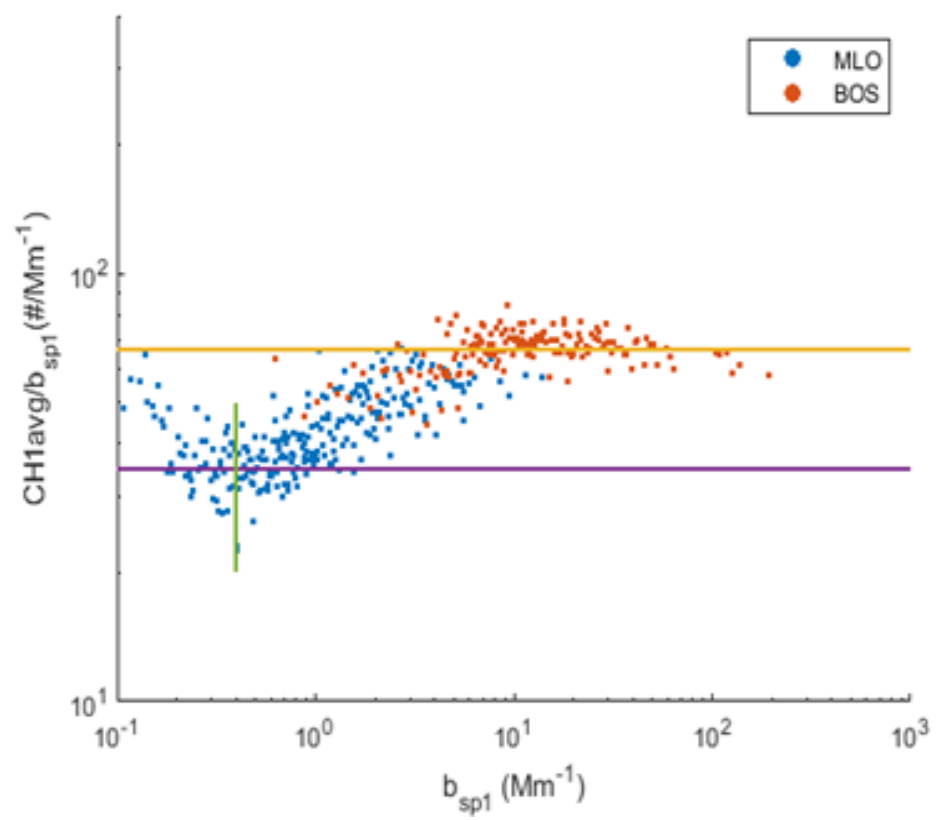

Figure 11. Ratios of $\mathrm{CH} 1 \mathrm{avg}$ and measured scattering, $b_{\mathrm{sp} 1}$, as a function of measured $b_{\mathrm{sp} 1}$ for MLO and BOS. Green line corresponds to $0.4 \mathrm{Mm}^{-1}$ while the purple line, a ratio of 35 , corresponds to the additive uncertainty of 14 . Yellow line corresponds to a $\mathrm{CH} 1 \mathrm{avg} / \mathrm{b}_{\mathrm{sp} 1}$ ratio of approximately 67 , the slope of $\mathrm{CH} 1$ avg vs. $\mathrm{b}_{\mathrm{sp} 1}$ above about $5 \mathrm{Mm}^{-1}$.

\subsubsection{Evaluating the use of the PA-PMS as a nephelometer}

The MLO and BOS hourly-average $\mathrm{CH} 1$ avg are plotted against $\mathrm{b}_{\mathrm{sp} 1}$, measured at $550 \mathrm{~nm}$, in Fig. 12. Also shown in Fig. 12 is an ordinary least squares (OLS) regression line with the intercept set equal to zero using the BOS and MLO combined dataset but with values associated with $b_{\mathrm{sp} 1}$ less than $0.4 \mathrm{Mm}^{-1}$ and greater than $500 \mathrm{Mm}^{-1}$ removed. Results of the regression for the combined datasets as well as for the individual BOS and MLO datasets are presented in Table 3. There is good agreement for both datasets (Table 3) with an $\mathrm{R}^{2}$ of 0.97 and 0.85 for the BOS and MLO datasets, respectively, and 0.97 for the combined datasets. The relationship deviates somewhat from linear with increasing slopes and scatter at lower values of atmospheric scattering coefficient, particularly for the MLO data. The slopes for all data, MLO, and BOS, are $0.015 \pm 2.07 \times 10^{-5}, 0.017 \pm 5.72 \times 10^{-5}$, and $0.015 \pm 2.68 \times 10^{-5}$, respectively. In the following analysis, a PA-derived atmospheric scattering $\left(b_{\mathrm{sp} 1, \mathrm{PA}}\right)$ for both $\mathrm{MLO}$ and BOS is estimated using $\mathrm{b}_{\mathrm{sp} 1, \mathrm{CH} 1}=$ $0.015 \times$ CH1 avg at a wavelength of $550 \mathrm{~nm}$. The "calibration" value of 0.015 corresponds to the 
yellow horizontal line in Fig. 11 of 67.0 (1/0.015) and corresponds to a median scattering diameter of about $0.33 \mu \mathrm{m}$ (Fig. 10).

Figure S16 shows that the submicron aerosol scattering coefficients at $550 \mathrm{~nm}$ and $700 \mathrm{~nm}$ are highly correlated, with the $700 \mathrm{~nm}$ scattering coefficient averaging $52 \%$ of the $550 \mathrm{~nm}$ scattering coefficient. This results in $b_{\mathrm{sp} 1, \mathrm{CH} 1}=0.0078 \times \mathrm{CH} 1$ avg at a wavelength of $700 \mathrm{~nm}$.

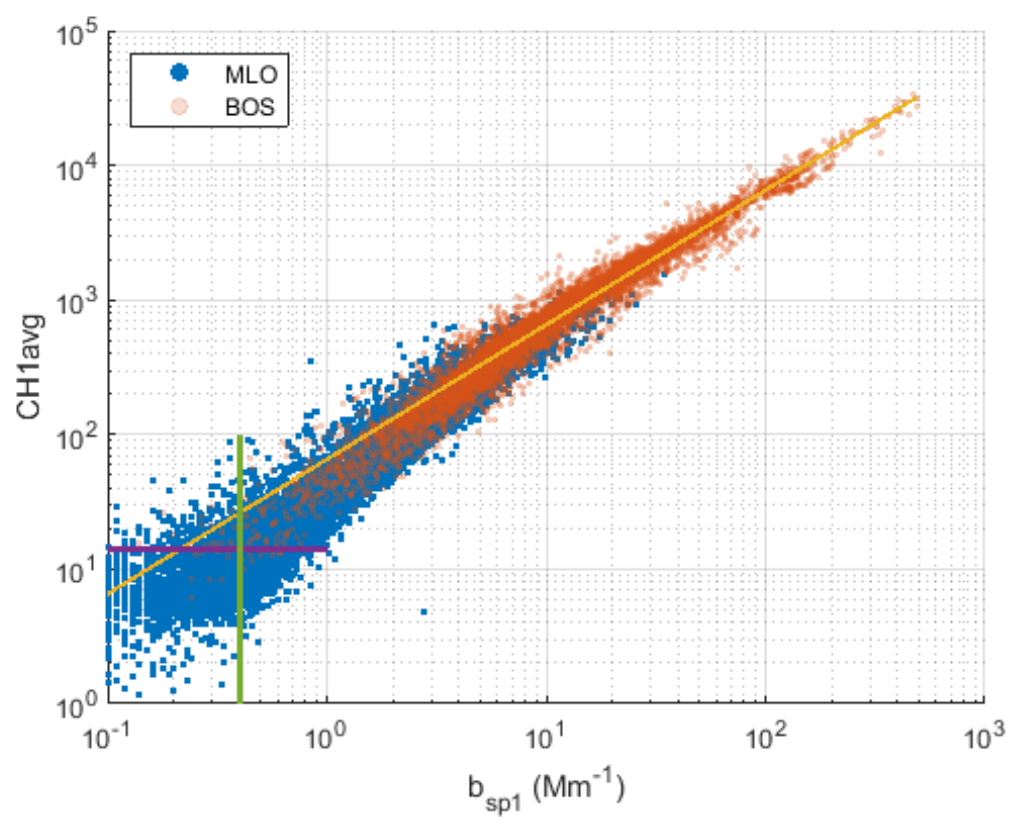

Figure 12. Fine aerosol scattering coefficient from TSI nephelometer vs. $\mathrm{CH} 1$ avg value from PA. Yellow line represents the fit to all data. Purple line shows the additive uncertainty of 14 while $b_{\text {sp } 1}$ values less than the green line were removed for the regression analysis.

Table 3. Ordinary least square regression coefficients with a zero intercept and standard error for $\mathrm{b}_{\mathrm{sp} 1}$ and $\mathrm{CH} 1$ as the dependent and independent variables, respectively, for the BOS, MLO, and combined datasets. $\mathrm{CH} 1$ and $b_{\text {sp } 1}$ reported at STP. Also shown are the respective coefficients of determination, $\mathrm{R}^{2}$.

\begin{tabular}{|l|l|l|l|l|}
\hline Site & slope & standard error & $\mathbf{1} /$ slope & $\mathbf{R}^{\mathbf{2}}$ \\
\hline BOS & 0.015 & $2.68 \times 10^{-5}$ & 67.0 & 0.97 \\
\hline MLO & 0.017 & $5.72 \times 10^{-5}$ & 59.0 & 0.85 \\
\hline Both BOS\&MLO & 0.015 & $2.07 \times 10^{-9}$ & 67.0 & 0.97 \\
\hline
\end{tabular}

As discussed above, the regression coefficient between $\mathrm{b}_{\mathrm{sp} 1}$ and $\mathrm{CH} 1$ for the combined dataset of 0.015 is used to estimate the $\mathrm{b}_{\mathrm{sp} 1, \mathrm{PA}}$ derived from the $\mathrm{CH} 1$ channel. The data for each dataset and the combined dataset were binned into ten bins based on measured $b_{\mathrm{sp} 1}$ levels that ranged from $0.4 \mathrm{Mm}^{-1}$ to $500 \mathrm{Mm}^{-1}$. Values of $b_{\mathrm{sp} 1}$ above $500 \mathrm{Mm}^{-1}$ were removed from the dataset. For each 
bin the normalized root mean square error (NRMSE) between $b_{\mathrm{sp} 1, \mathrm{PA}}$ and measured $b_{\mathrm{sp} 1}$ was calculated. The NRMSE values as a function of the $b_{\text {sp } 1}$ bins are plotted in Fig. 13 for the combined dataset represented as the gray bars and BOS and MLO represented by blue and orange bars, respectively.

For $b_{\text {sp } 1}$ levels less than $0.8 \mathrm{Mm}^{-1}$, the NRMSE is $45-55 \%$, and for $b_{\text {sp } 1}$ levels greater than 10 $\mathrm{Mm}^{-1}$, the NRMSE is about $25 \%$ or less. For $\mathrm{b}_{\mathrm{sp} 1}$ levels greater than $60 \mathrm{Mm}^{-1}$, the NRMSE 772 approaches $15 \%$.

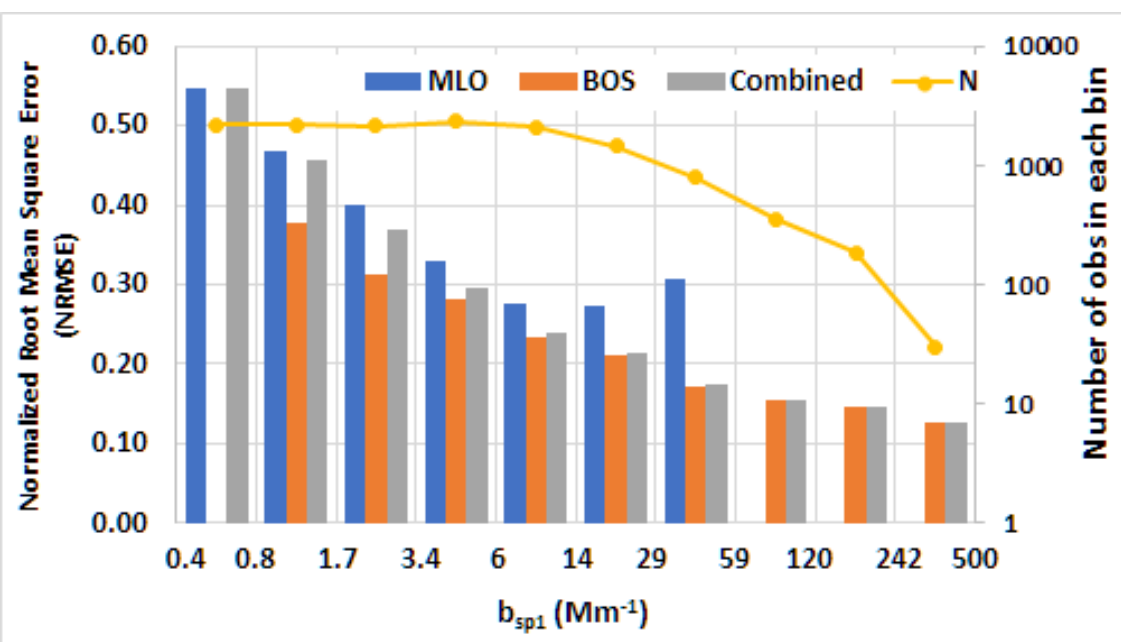

Figure 13. Normalized root mean square error between measured and estimated scattering from $\mathrm{CH} 1$ values plotted as a function of binned $b_{\mathrm{sp} 1}$ for the BOS, MLO, and combined datasets. Yellow line is referenced to the right axis to provide the number of observations in each bin. Numbers on the $\mathrm{x}$-axis represent the lower and upper levels of each scattering bin.

As discussed in Sect. 2.2.9, the uncertainty for high CH1avg values is small (1.9\% to 4.8\%). The precision of the TSI 3563 nephelometer is also similarly high, and together they account for about $10 \%$ NRMSE at high $b_{\text {sp } 1}$ values.

The overall normalized error is likely due to a variety of sources, primarily the variability in the $\mathrm{CH} 1$ values due to using a polarized light source and truncation errors due to the geometry of the PA-PMS sensors. Also, the variability in aerosol characteristics such as size distribution, refractive index, and shape may be important. At extremely low levels, uncertainty may also be due to a nonuniform distribution of particles in the PMS laser beam.

\subsubsection{PA-PMS size distributions and PM2.5}

The aerosol number concentrations from the six PMS size channels are unrealistic. The BOS field data showed that the concentration of particles larger than $0.3 \mu \mathrm{m}$ diameter calculated from the DMPS averaged 10 times higher than CH1 (Fig. S17). The other PMS size channels are so highly correlated with $\mathrm{CH} 1$ that they provide no additional information (Table S3). Furthermore, it appears that the PMS creates an approximately invariant normalized aerosol number distribution across a wide range of sites (Table S4, Fig. S18). Although the overall CH1 
concentration can vary over 6 orders of magnitude (column 3 in Table S4), the shape of the PMS size distribution remains fairly constant. This suggests that the values in the channels above $\mathrm{CH} 1$ are software generated and indicates that the most relevant output from the PMS is from the $\mathrm{CH} 1$ channel. The bottom row of Table S4 shows that the PMS bin fractions above $1 \mu \mathrm{m}$ increased by only a factor of $2-5$ in a high-PM2.5 windblown dust episode at Keeler, California. This is consistent with the PMS model prediction that PMS coarse aerosol response is small relative to a 799 perfect nephelometer.

800 The PM2.5 was not measured by Federal Reference Method (FRM) or Federal Equivalent 801 Method (FEM) instruments at MLO and BOS during this study. As a result, this study cannot 802 compare the PA-PMS PM2.5 channel results with these methods. Figure S19 shows that the PAPMS PM2.5 channel is reasonably well correlated with $b_{\mathrm{sp} 1}$ for values greater than about 10-20 $\mu \mathrm{g} \mathrm{m}^{-3}$, typical of many moderately polluted locations, with a calculated mass scattering efficiency of approximately $2.5 \mathrm{~m}^{2} \mathrm{~g}^{-1}$. However, it is likely that the PA-PMS underestimates PM2.5 for very clean areas where $b_{\mathrm{sp} 1}$ is often less than $10 \mathrm{Mm}^{-1}$. For example, the PA-PMS PM2.5 was zero for 1099 of the hours in this study when $b_{\text {sp } 1}$ was greater than $1 \mathrm{Mm}^{-1}$.

The results above indicate that $\mathrm{CH} 1$ is the primary source of aerosol information from the PMS

809 sensor. However, consistent with the sensor behaving like a cell-reciprocal nephelometer, it was 810 found that $\mathrm{CH} 1$ was not the number concentration of particles having diameters greater than 0.3 $811 \mu \mathrm{m}$. CH1 was approximately a factor of 10 lower than the DMPS number concentration for a 812 similar size range.

\section{6. Summary, Discussion, and Future Work}

814 We have demonstrated that the PMS sensor inside the PA monitor (PA-PMS) appears to behave 815 as an imperfect, reciprocal integrating nephelometer. As a scattering sensor, the PMS cannot 816 directly count nor size particles in the air stream. The PMS uses an unknown algorithm to 817 convert the scattering signal to a near-constant normalized number distribution from which PM 818 concentrations are derived.

819 The scattering coefficient that is measured by an ideal integrating nephelometer does not need 820 correction for any aerosol attributes such as shape, chemical composition, refractive index, or diameter. It is a valuable measure for visibility and global climate monitoring. Simple low-cost sensors such as the PA-PMS can play a role in estimating aerosol scattering coefficients and improving global coverage. Yearlong field data at NOAA's Mauna Loa Observatory and Boulder Table Mountain sites show that the $1 \mathrm{~h}$ average of the PA-PMS CH1 is highly correlated with a nephelometer-measured fine aerosol scattering coefficient at $550 \mathrm{~nm}, \mathrm{~b}_{\mathrm{sp} 1}$, over a wide scattering coefficient range of $0.4 \mathrm{Mm}^{-1}$ to $500 \mathrm{Mm}^{-1}$. The relationship between $\mathrm{CH} 1$ and $\mathrm{b}_{\mathrm{sp} 1}$ at $550 \mathrm{~nm}$ is found to be $b_{\mathrm{sp} 1}=0.015 \times \mathrm{CH} 1$ when both quantities are adjusted to the same temperature and pressure. data may motivate users of other low-cost sensors to develop similar models. It is possible that 
835 The strong relationship between $\mathrm{b}_{\mathrm{sp} 1}$ and $\mathrm{CH} 1$ and the agreement between the model and field data support characterizing the PA-PMS as an imperfect truncated cell-reciprocal nephelometer. The results demonstrate that it is possible to use the PA-PMS to estimate the $1 \mathrm{~h}$ average fine aerosol scattering coefficient across a wide range of aerosol scattering concentrations, provided the aerosol median scattering diameter is between $0.26 \mu \mathrm{m}$ and $0.46 \mu \mathrm{m}$. The $\mathrm{CH} 1$ and $\mathrm{b}_{\mathrm{sp} 1}$ relationship is dependent on the size distribution, and it is expected to change for locations and times where the particle size shifts to larger or smaller sizes than those measured at BOS and 842 MLO.

843 We found that the PA-PMS has important limitations compared to integrating nephelometers. It measures the light scattering over a smaller angular range, causing a significant truncation of the scattering signal in the forward and backward directions. Nephelometers calibrate their scattering coefficient with $\mathrm{CO}_{2}$ or Suva, but the PMS is unresponsive to these gases. As a result, there is currently no convenient way to calibrate the PMS to ensure its accuracy. Neither PA nor Plantower provide technical support. Quality assurance and control are not as robust as one encounters for regulatory and scientific monitoring instruments. For this reason, it is useful to test the PMS sensors in filtered air before using them and to limit field use to those sensors that have $1 \mathrm{~h}$ average $\mathrm{CH} 1$ values less than 2 . While sampling, it is necessary to compare $1 \mathrm{~h}$ averages from the two PMS sensors in each PA monitor to become aware of any changes and, if needed, to replace them in a timely fashion.

854 This study limited its findings to low-RH air, because both the PA monitors and the nephelometers were heated to reduce $\mathrm{RH}$. Since $\mathrm{RH}$ plays such an important role in water uptake by hygroscopic aerosols and the concomitant increase in the scattering coefficient, future work is planned to compare unheated PA monitors with an unheated nephelometer that does not reduce $\mathrm{RH}$ before sampling. Our model predicts that the PMS may not be as responsive to hygroscopic growth as an unheated nephelometer. This would imply that the PMS might underestimate highRH, low-visibility aerosol scattering coefficients. 


\section{Appendix}

863 The PMS physical-optical model makes some simplifying assumptions. The actual PMS laser

864 beam profile is not a simple plane wave but complex in shape. The model assumes the laser is a 865 plane wave with a constant laser beam irradiance profile. This allows the use of Mie theory to 866 predict the light scattered by particles in the laser. Secondly, the model calculates the light 867 scattered to a narrow strip across the middle instead of the entire photodiode. It assumes that the 868 irradiance received by the narrow strip is representative of the entire photodiode.

869 The intensity of light scattered from a particle in the laser is

where $I(\theta)$ is the intensity of light at angle $\theta$ scattered from a particle in the volume element dv (with units of Watt sr-1); $\beta(\theta)$ is the volume scattering function $\left(\mathrm{m}^{-1} \mathrm{sr}^{-1}\right) ; \mathrm{F}_{\mathrm{dv}}$ is the incident laser flux density (Watt $\mathrm{m}^{-2}$ ) impinging on the volume element $\mathrm{dv}$; and $\mathrm{dv}$ is the volume element

874 within the laser.

875 The volume scattering function for a monodisperse aerosol having a diameter $\mathrm{D}_{\mathrm{p}}$ and number 876 concentration $\mathrm{N}\left(\mathrm{D}_{\mathrm{p}}\right)$ in the PMS laser is

878

879

880

881

882 where $\left|S_{1}\left(m, \lambda, \theta, D_{p}\right)\right|^{2}$ is the perpendicular scattering intensity function; $\lambda$ is the laser wavelength; $m$ is the particle complex refractive index; $\theta$ is the scattering angle; and $D_{p}$ is the aerosol diameter. Note that $\theta=0$ in the direction of the laser, and $\theta=90$ degrees perpendicular to the laser and photodiode.

For one particle of size Dp in the volume element dv, $N(D p) d v=(1 / d v) \times(d v)=1$.

The incremental power $\mathrm{dP}$ (Watt) scattered from a particle in the volume element $\mathrm{dv}$ across a solid angle $\mathrm{d} \boldsymbol{\Omega}$ subtended on the surface of a sphere at distance $r$ from the particle, and normal to $\mathrm{r}$, is

$\mathrm{dP}=\mathrm{I}(\theta) \mathrm{d} \boldsymbol{\Omega}$.

$\mathrm{d} \boldsymbol{\Omega}=\mathrm{dA}_{0} / \mathrm{r}^{2}$, where $\mathrm{dA}_{0}$ is the incremental area on the sphere at distance $\mathrm{r}$ from the particle and normal to $\mathrm{r}$. $\mathrm{dP}$ is then

$\mathrm{dP}=\mathrm{I}(\theta) \mathrm{dA}_{0} / \mathrm{r}^{2}$.

For the PMS model, $\mathrm{dA}_{0}$ is a small rectangle with width $\mathrm{w}$ and height $\mathrm{rd} \theta$, where $\mathrm{w}$ is the width of the strip on the photodiode, and $\mathrm{d} \theta$ is the differential scattering angle.

$\mathrm{dA}_{0}=\mathrm{rd} \theta \times \mathrm{w}$, where $\mathrm{w}$ is the width of the strip on the photodiode. From Fig. A1, $r=b / \sin (\theta)$, where $b$ is the distance from the laser to the photodiode. 
$\mathrm{d} \boldsymbol{\Omega}=\mathrm{dA}_{0} / \mathrm{r}^{2}=(\mathrm{rd} \theta \times \mathrm{w}) / \mathrm{r}^{2}=\mathrm{d} \theta \times(\mathrm{w} / \mathrm{r})=(\mathrm{w} / \mathrm{b}) \times \sin (\theta) \mathrm{d} \theta$.

895 The incremental power across the solid angle $\mathrm{d} \boldsymbol{\Omega}$ normal to $\mathrm{r}$ is then

$896 \mathrm{dP}=\mathrm{I}(\theta) \times \mathrm{dA}_{0} / \mathrm{r}^{2}=\mathrm{I}(\theta) \times(\mathrm{w} / \mathrm{b}) \times \sin (\theta) \mathrm{d} \theta$.

897 Substituting for $\mathrm{I}(\theta)$,

$\mathrm{dP}(\mathrm{g}, \mathrm{x}, \theta)=\left[\mathrm{F}_{0}(\lambda / 2 \pi)^{2}\left|\mathrm{~S}_{1}\left(\theta, \mathrm{D}_{\mathrm{p}}\right)\right|^{2}\right] \times(\mathrm{w} / \mathrm{b}) \times \sin (\theta) \mathrm{d} \theta$

899 Equation A5 can be further simplified by combining the constants into $K=(\lambda / 2 \pi)^{2} \mathrm{~F}_{0} \mathrm{w} / \mathrm{b}$, where

$900 \mathrm{~K}$ has units of watts:

901

$\mathrm{dP}(\mathrm{g}, \mathrm{x}, \theta)=\mathrm{K}\left|\mathrm{S}_{1}\left(\theta, \mathrm{D}_{\mathrm{p}}\right)\right|^{2} \sin (\theta) \mathrm{d} \theta$.

902 The power received by the photodiode from a particle of diameter $D_{p}$ in the volume element at $x$

903 is obtained by numerically integrating across $\theta$ on the photodiode:

$\mathrm{P}\left(\mathrm{m}, \mathrm{D}_{\mathrm{p}}\right)=\mathrm{K} \int_{\boldsymbol{\theta} \mathbf{1}(\boldsymbol{x})}^{\boldsymbol{\theta 2}(\boldsymbol{x})} \quad\left|\mathrm{S}_{1}\left(\mathrm{~m}, \theta, \mathrm{D}_{\mathrm{p}}\right)\right|^{2} \sin (\theta) \mathrm{d} \theta$.

905

906

907

908

909

910

911

912

913

914

915

916

917

Due to the PMS geometry, the upper and lower angular scattering integration limits for $\theta$ depend on the location $\mathrm{x}$. This can be seen in Fig. S4. For example, at $\mathrm{x}=0 \mathrm{~mm}$, the upper and lower integration limits for $\theta$ are 18 to 38 degrees. At $\mathrm{x}=4.0 \mathrm{~mm}$, over the center of the photodiode, the angular integration limits are 50 to 130 degrees.

The total power $\mathrm{P}$ in Watts received by the photodiode from the light scattered by all the particles of diameter $\mathrm{D}_{\mathrm{p}}$ in the laser is obtained by carrying out the numerical integration in Eq. A7 for all $\mathrm{x}$ from 0 to $10 \mathrm{~mm}$ :

$\mathrm{P}\left(\mathrm{m}, \mathrm{D}_{\mathrm{p}}\right)=\mathrm{K} \int_{x=0}^{x=10 \mathrm{~mm}} \quad \int_{\theta 1(x)}^{\theta 2(x)}\left|\mathrm{S}_{1}\left(\mathrm{~m}, \theta, \mathrm{D}_{\mathrm{p}}\right)\right|^{2} \sin (\theta) \mathrm{d} \theta \mathrm{dx}$.

The result for carrying out this calculation for the power per particle of size $\mathrm{D}_{\mathrm{p}}$ is in Table $\mathrm{S} 5$ for wavelength $657 \mathrm{~nm}$ and particle refractive index $1.53-0.015 \mathrm{i}$. The total power received at the photodiode by a distribution of particles is obtained by summing up the power per particle of size $D_{p}$ times the number of particles $N\left(D_{p}, m\right)$ in the size interval $D_{p}$ to $D_{p}+d D_{p}$.

$\mathrm{P}=\mathrm{K} \int_{D p} \quad \int_{x=0}^{x=10 m m} \quad \int_{\theta 1(x)}^{\theta 2(x)} \quad\left|\mathrm{S}_{1}\left(\mathrm{~m}, \theta, \mathrm{D}_{\mathrm{p}}\right)\right|^{2} \sin (\theta) \mathrm{N}\left(\mathrm{D}_{\mathrm{p}}, \mathrm{m}\right) \mathrm{d} \theta \mathrm{dx} \mathrm{dD}_{\mathrm{p}}$

Figure A1 shows the PMS geometry. The distance along the laser is the variable $\mathrm{x}$, which ranges from 0 to $10 \mathrm{~mm}$. The distance along the photodiode is the variable $\mathrm{g}$, which ranges from 0 to 3.0 $\mathrm{mm}$. The distance between the photodiode and the laser is b, approximately $1.8 \mathrm{~mm}$. 


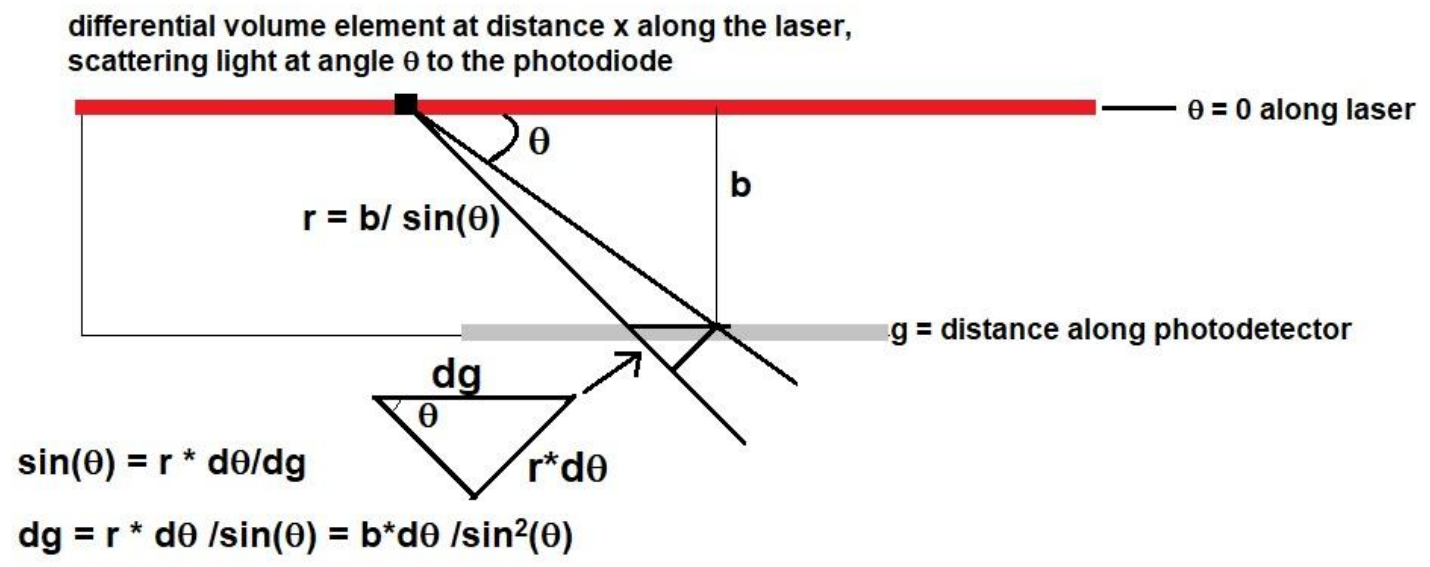

$921 \quad$ Figure A1. Sketch of PMS5003 geometry.

\section{Acknowledgements}

923 The authors acknowledge the following for their contributions:

924 Jim Wendell, NOAA, for engineering support, Marty Martinsen, NOAA, for MLO field support,

925 Derek Hageman, CIRES, University of Colorado, for data acquisition and processing support,

926 and Helene Bennett, CIRA, Colorado State University, for technical editing support. The

927 National Park Service participation in this project was supported under the cooperative

928 agreement P17AC00971.

\section{Disclaimer}

930 The assumptions, findings, conclusions, judgments, and views presented herein are those of the 931 authors and should not be interpreted as necessarily representing NOAA or National Park 932 Service policies. Reference to any companies or specific commercial products does not 933 constitute endorsement by NOAA or the National Park Service.

\section{References}

935 Abu-Rahmah, A., Arnott, W.P., and H Moosmüller, H. Integrating nephelometer with a low 936 truncation angle and an extended calibration scheme. Measurement Science and Technology, 937 Volume 17, Number 7. 2006. https://doi.org/10.1088/0957-0233/17/7/010.

938 Anderson, T. L. and Ogren, J. A. (1998) Determining Aerosol Radiative Properties Using the 939 TSI 3563 Integrating Nephelometer, Aerosol Science and Technology, 29:1, 57-69, 940 doi: $10.1080 / 02786829808965551$.

941 Anderson, T. L., Covert, D. S., Marshall, S. F., Laucks, M. L., Charlson, R. J., Waggoner, A. P., 942 Ogren, J. A., Caldow, R., Holm, R., Quant, F., Sem, G., Wiedensohler, A., Ahlquist, N. A., and 943 Bates, T. S. (1996). Performance Characteristics of a High-Sensitivity, Three-Wavelength, Total 944 Scatter/Backscatter Nephelometer, J. Atmos. Oceanic Technol. 13: 967-986. 
945 Andrews, E., Sheridan, P., Ogren, J.A., Hageman, D., Jefferson, A., Wendell, J., Alastuey, A., 946 Alados-Arboledas, L., Bergin, M., Ealo, M., Hallar, A.G., Hoffer, A., Kalapov, I., Keywood, M., 947 Kim, J., Kim, S.-W., Kolonjari, F., Labuschagne, C., Lin, N.-H., Macdonald, A., Mayol-Bracero, 948 O.L., McCubbin, I.B., Pandolfi, M., Reisen, F., Sharma, S., Sherman, J. P., Sorribas, M., Sun, J., 949 "Overview of the NOAA/ESRL Federated Aerosol Network" Bull. Amer. Meteor. Soc., 100, 950 123-135, doi:10.1175.BAMS-D-17-0175.1, 2019.

951 Arnott, W. P.; Walker, J. W.; Moosmuller, H.; Elleman, R. A.; Haflidi, H.; Buzorius, G.; Conant, 952 W. C.; Flagan, R. C.; Seinfeld, J. H., (2006). "Photoacoustic Insight for Aerosol Light 953 Absorption Aloft from Meteorological Aircraft and Comparison with Particle Soot Absorption 954 Photometer Measurements: The DOE Southern Great Plains Climate Research Facility and the 955 Coastal Stratocumulus Imposed Perturbation Experiments." Journal of Geophysical Research, 956 111, D05S02, doi:10.1029/2005JD005964.

957 Barkjohn, K.K., Gantt, B., and Clements, A.L., "Development and application of a United States 958 wide correction for PM2.5 data collected with the PurpleAir Sensor," Atmos. Meas. Tech.

959 Discuss., [preprint], https://doi.org/10.5194/amt-2020-413, in review, 2020.

960 Beuttell, R. G. and Brewer, A.W.: Instruments for the measurement of the visual range, J. Sci.

961 Instr. Phys. Ind., 26, 357-359, 1949.

962 Bodhaine, B.A. and Mendonca, B.G (1974) Preliminary four wavelength nephelometer 963 measurements at Mauna Loa Observatory. Geophys. Res. Lett., 1, \#3, 119-122.

964 Bodhaine, B.A., Mendonca, B.G., Harris, J.M. and Miller, J.M. (1981). Seasonal variations in 965 aerosols and atmospheric transmission at Mauna Loa Observatory. J. Geophys. Res. 86: 7395966 7398. https://doi.org/10.1029/JC086iC08p07395.

967 Bohren, C.F. and Huffman, D.R. Absorption and Scattering of Light by Small Particles. 1983. 968 John Wiley \& Sons.

969 Butcher, S.S., and Charlson, R.J. (1972), An Introduction to Air Chemistry. Academic Press, pp. 970 256, https://doi.org/10.1016/B978-0-12-148250-3.X5001-X.

971 Chambers, S.D., Zahorowski, W., Williams, A.G., Crawford, J., and Griffiths, A.D. (2013), 972 Identifying tropospheric baseline air masses at Mauna Loa Observatory between 2004 and 2010 973 using Radon-222 and back trajectories, J. Geophys. Res. Atmos., 118, 992-1004, 974 doi:10.1029/2012JD018212.

975 Currie, L. "Limits for Qualitative Detection and Quantitation: Application to Radiochemistry", 976 Anal. Chem. 40, 586-593 (1968).

977 Friedlander, S.K., Smoke, Dust, and Haze: Fundamentals of Aerosol Behavior, 1977, Wiley978 Interscience. Page75.

979 Gliss, J., Mortier, A., Schulz, M., Andrews, E., Balkanski, Y., Bauer, S.E., Benedictow, A.M.K., 980 Bian, H., Checa-Garcia, R., Chin, M., Ginoux, P., Griesfeller, J.J., Heckel, A., Holben, B.N., 981 Kinne, S., Kipling, Z., Kirkevag, A., Kokkola, H. Laj, P., Le Sager, P., Levy, R., Lund, M.T., 
982 Lund Myhre, C., Matsui, H., Myhre, G., Neubauer, D., van Noije, T., North, P., Olivie, D.J.L., 983 Sogacheva, L., Takemura, T., Tsigaridis, K., Tsyro, S.G., "AeroCom phase III multi-model 984 evaluation of the aerosol lifecycle and optical properties using ground and space based remote 985 sensing as well as surface in situ observations," Atmos. Chem. Phys., 21, 87-128, 986 doi:10.5194/acp-21-87-2021, 2021.

987 Grinshpun, S., Willeke, K., and Kalatoor, S. A general equation for aerosol aspiration by thin988 walled sampling probes in calm and moving air. Atmospheric Environment. Part A. General 989 Topics. Volume 27, Issue 9, June 1993, Pages 1459-1470. https://doi.org/10.1016/0960$990 \quad$ 1686(93)90132-I.

991 Gupta, P., Doraiswamy, P., Levy, R., Pikelnaya, O., Maibach, J., Feenstra, B., et al. (2018). 992 Impact of California fires on local and regional air quality: The role of a low-cost sensor network 993 and satellite observations. GeoHealth, 2, 172-181.

994 Hagan, D. and Kroll, J. 2020. Assessing the accuracy of low-cost optical particle sensors using a 995 physics-based approach. Atmos. Meas. Tech., 13, 6343-6355, 2020.

996 Hangal, S. and Willeke, K. 1990. Aspiration Efficiency: A Unified Model for all Forward 997 Sampling Angles, ES\&T, 24, 688-690.

998 Harris, J.M. and Kahl, J.D. (1990). A descriptive atmospheric transport climatology for the 999 Mauna Loa Observatory, using clustered trajectories. J. Geophys. Res. 95: 13651-13667. 1000 https://doi.org/10.1029/JD095iD09p13651.

1001 He, M., Kuerbanjiang, N. and Dhaniyala, S. Performance characteristics of the low-cost 1002 Plantower PMS optical sensor, Aerosol Science and Technology, 54(2), 232-241, 1003 doi:10.1080/02786826.2019.1696015, 2020.

1004 Heintzenberg, J., and Charlson, R. J. (1996). The Integrating Nephelometer: A Review, J. 1005 Atmos. Oceanic Technol., 13:987-1000.

1006 Heintzenberg, J., Wiedensohler, A., Tuch, T. M., Covert, D. S., Sheridan, P., Ogren, J. A., Gras, 1007 J., Nessler, R., Kleefeld, C., Kalivitis, N., Aaltonen, V., Wilhelm, R., \& Havlicek, M. (2006). 1008 Intercomparisons and Aerosol Calibrations of 12 Commercial Integrating Nephelometers of 1009 Three Manufacturers, Journal of Atmospheric and Oceanic Technology, 23(7), 902-914.

1010 Hering, S.V., "Impactors, Cyclones, and Other Inertial and Gravitational Collectors," p 284, in 1011 Air Sampling Instruments for Evaluation of Atmospheric Contaminants, 8th ed, B.Cohen, S.V. 1012 Hering, Eds., American Conference of Governmental Industrial Hygienists, Cincinnati, OH 1013 (1995).

1014 Holder, A.L.; Mebust, A.K.; Maghran, L.A.; McGown, M.R.; Stewart, K.E.; Vallano, D.M.; 1015 Elleman, R.A.; Baker, K.R. Field Evaluation of Low-Cost Particulate Matter Sensors for 1016 Measuring Wildfire Smoke. Sensors, 2020, 20, 4796.

1017 Hyslop, N. and White, W., An empirical approach to estimating detection limits using collocated 1018 data. Environ. Sci. Technology. 2008, 42, 5235-5240. 
1019 Hyslop, N., and White, W., Estimating precision using duplicate measurements. ISSN:1047-

10203289 J. Air \& Waste Manage. Assoc., 59:1032-1039, DOI:10.3155/1047-3289.59.9.1032, 2009.

1021 Jayaratne, R., Liu, X., Ahn, K.H., Asumadu-Sakyi, A., Fisher, G., Gao, J., Mabon, A., Mazaheri,

1022

1023

1024

1025

1026

1027

1028

1029

1030

1031

1032

1033

1034

1035

1036 M., Mullins, B., Nyaku, M., Ristovski, Z., Scorgie, Y., Thai, P., Dunbabin, M. and Morawska, L. (2020). Low-cost PM2.5 Sensors: An Assessment of their Suitability for Various Applications. Aerosol Air Qual. Res. 20: 520-532. https://doi.org/10.4209/aaqr.2018.10.0390.

JCGM100:GUM, "Guide to the Expression of Uncertainty in Measurement," International Standardization Organization: Geneva, Switzerland, https://www.bipm.org/en/publications/guides/gum.html, accessed 22 March 2021, 2008.

Kelly, K.E., Whitaker, J., Petty, A., Widmer, C., Dybwad, A., Sleeth, D., Martin, R., and Butterfield, A., "Ambient and laboratory evaluation of a low-cost particulate matter sensor," Environ. Pollut. 221, 491-500. https://doi.org/10.1016/j.envpol.2016.12.039, 2017.

Kulkarni, P., Baron, P., and Willeke, K. Aerosol Measurement: Principles, Techniques, and Applications, 3rd Edition. Section 6.2, "Sample Extraction". John Wiley \& Sons, ISBN: 978-0470-38741-2 July 2011.

Kuula, J., Makela, T., Aurela, M., Teinila, K., Varjonen, S., Gonzalez, O., and Timonen, H.: Laboratory evaluation of particle-size selectivity of optical low-cost particulate matter sensors, Atmos. Meas. Tech., 13, 2413-2423, https://doi.org/10.5194/amt-13-2413-2020, 2020.

Laj, P., Bigi, A., Rose, C., Andrews, E., Lund Myhre, C., Collaud Coen, M., Wiedensohler, A., Schulz, M., and 90 co-authors, "A global analysis of climate-relevant aerosol properties retrieved from the network of GAW near-surface observatories," Atmos. Meas. Tech., 13, 4353-4392, https://doi.org/10.5194/amt-13-4353-2020, 2020.

Malings, Carl, Rebecca Tanzer, Aliaksei Hauryliuk, Provat K. Saha, Allen L. Robinson, Albert A. Presto \& R Subramanian (2020) Fine particle mass monitoring with low-cost sensors: Corrections and long-term performance evaluation, Aerosol Science and Technology, 54:2, 160174, DOI: $10.1080 / 02786826.2019 .1623863$.

Malm, W.C., Sisler, J.F., Huffman, D., Eldred, R.A., Cahill, T.A., 1994. Spatial and seasonal trends in particle concentration and optical extinction in the United States. Journal of Geophysical Research 99 (D1), 1347-1370.

Markowicz, K.M. and Chilinski, M.T., "Evaluation of Two Low-Cost Optical Particle Counters for the Measurement of Ambient Aerosol Scattering Coefficient and Ångström Exponent," Sensors, 20, 2617; doi:10.3390/s20092617, www.mdpi.com/journal/sensors, 2020.

Mehadi, Ahmed; Hans Moosmüller, David E. Campbell, Walter Ham, Donald Schweizer, Leland Tarnay \& Julie Hunter (2020): Laboratory and field evaluation of real-time and near real-time PM2.5 smoke monitors, Journal of the Air \& Waste Management Association, DOI: 10.1080/10962247.2019.1654036. 
1055 Middleton, W. E. K., (1952), in Vision Through the Atmosphere, pp. 203-206. The University of

1056 Toronto Press, Toronto, Canada.

1057 Miller, J.M. (1981). A five-year climatology of back trajectories from the Mauna Loa

1058 Observatory, Hawaii. Atmos. Environ. 15: 1553-1558. https://doi.org/10.1016/0004-

1059 6981(81)90138-4.

1060 Molenar, J. V.: Analysis of the real world performance of the Optec NGN-2 ambient

1061 nephelometer, Visual Air Quality: Aerosols and Global Radiation Balance, Air and Waste

1062 Management Associa- tion, Pittsburgh, 243-265, 1997.

1063 Morawska L, Thai PK, Liu X, Asumadu-Sakyi A, Ayoko G, Bartonova A, Bedini A, Chai F,

1064

1065

1066

1067

1068

1069 Christensen B, Dunbabin M, Gao J, Hagler GSW, Jayaratne R, Kumar P, Lau AKH, Louie PKK, Mazaheri M, Ning Z, Motta N, Mullins B, Rahman MM, Ristovski Z, Shafiei M, Tjondronegoro D, Westerdahl D, Williams R. Applications of low-cost sensing technologies for air quality monitoring and exposure assessment: How far have they gone? Environ Int., 2018, 116:286-299. doi: 10.1016/j.envint.2018.04.018. Epub 2018 Apr 26. PMID: 29704807; PMCID: PMC6145068.

1070 Mulholland, G. W., and Bryner, N. P. (1994). Radiometric Model of the Transmission Cell1071 Reciprocal Nephelometer. Atmos. Environ., 28: 873-887.

1072

1073

1074

1075

1076

1077

1078

1079

1080

1081

1082

1083

1084

1085

1086

1087

1088

1089

1090

1091

1092

Müller, T., Laborde, M., Kassell, G., and Wiedensohler, A.: Design and performance of a threewavelength LED-based total scatter and backscatter integrating nephelometer, Atmospheric Measurement Techniques, 4, 1291-1303, https://doi.org/10.5194/amt-4-1291-2011, 2011.

Nakayama, T., Suzuki, H., Kagamitani, S., Ikeda, Y., Uchiyama, A., and Matsumi, Y. (2015). Characterization of a Three Wavelength Photoacoustic Soot Spectrometer (PASS-3) and a Photoacoustic Extinctiometer (PAX), J. Meteorol. Soc. Jpn., 93, 285-308.

Naqwi, A. and F. Durst, 1990, Focusing of diode laser beams: a simple mathematical model, Applied Optics, Vol. 29, No. 12, 1780-1785.

Pandolfi, M., Alados-Arboledas, L., Alastuey, A., Andrade, M., Angelov, C., Artiñano, B., Backman, J., Baltensperger, U., Bonasoni, P., Bukowiecki, N., Collaud Coen, M., Conil, S., Coz, E., Crenn, V., Dudoitis, V., Ealo, M., Eleftheriadis, K., Favez, O., Fetfatzis, P., Fiebig, M., Flentje, H., Ginot, P., Gysel, M., Henzing, B., Hoffer, A., Holubova Smejkalova, A., Kalapov, I., Kalivitis, N., Kouvarakis, G., Kristensson, A., Kulmala, M., Lihavainen, H., Lunder, C., Luoma, K., Lyamani, H., Marinoni, A., Mihalopoulos, N., Moerman, M., Nicolas, J., O'Dowd, C., Petäjä, T., Petit, J.-E., Pichon, J. M., Prokopciuk, N., Putaud, J.-P., Rodríguez, S., Sciare, J., Sellegri, K., Swietlicki, E., Titos, G., Tuch, T., Tunved, P., Ulevicius, V., Vaishya, A., Vana, M., Virkkula, A., Vratolis, S., Weingartner, E., Wiedensohler, A., and Laj, P.: A European aerosol phenomenology -6 : scattering properties of atmospheric aerosol particles from 28 ACTRIS sites, Atmos. Chem. Phys., 18, 7877-7911, https://doi.org/10.5194/acp-18-7877-2018, 2018.

Papapostolou, Vasileios, Hang Zhang, Brandon J. Feenstra, Andrea Polidori, Development of an environmental chamber for evaluating the performance of low-cost air quality sensors under 
1095 Pawar, H. and Sinha, B (2020) Humidity, density, and inlet aspiration efficiency correction

1096 improve accuracy of a low cost sensor during field calibration at a suburban site in the NorthWestern Indo-Gangetic plain (NM-IGP). Aerosol Science and Technology, 54-6 685-703.

1098

1099

1100

1101

1102

1103

1104

1105

1106

1107

1108

1109

1110

1111

1112

1113

1114

1115

1116

1117

1118

1119

1120

1121

1122

1123

1124

1125

1126

1127

1128

1129
Peñaloza-Murillo, M. (1999). Deriving the basic cell-reciprocal integrating nephelometer equation and its use for calibration purposes: a comprehensive approach. Measurement Science and Technology. 10. R1. doi:10.1088/0957-0233/10/1/003.

Ryan, S. (1997). The wind field around Mauna Loa derived from surface and balloon observations. J. Geophys. Res. 102: 10711-10725. https://doi.org/10.1029/97JD00646

Sayahi, T., Butterfield, A. and Kelly, K. E.: Long-term field evaluation of the Plantower PMS low-cost particulate matter sensors, Environ. Poll., 245, 932-940, https://doi.org/10.1016/j.envpol.2018.11.065, 2019.

Shaw, G.E. (1980). Transport of Asian Desert Aerosol to the Hawaiian Islands. J. Appl. Meteorol. 19:1254-1259. https://doi.org/10.1175/15200450(1980)019<1254:TOADAT $>2.0 . \mathrm{CO} ; 2$

Sherman, J. P., Sheridan, P. J., Ogren, J. A., Andrews, E., Hageman, D., Schmeisser, L., Jefferson, A., and Sharma, S.: A multi-year study of lower tropospheric aerosol variability and systematic relationships from four North American regions, Atmos. Chem. Phys., 15, 1248712517, https://doi.org/10.5194/acp-15-12487-2015, 2015.

Snider, G., Weagle, C. L., Martin, R. V., Van Donkelaar, A., Conrad, K., Cunningham, D., Gordon, C., Zwicker, M., Akoshile, C., Artaxo, P., Anh, N.X., Brook, J., Dong, J., Garland, R.M., Greenwald, R., Griffith, D.,He, K., Holben, B.N., Kahn, R., Koren, I., Lagrosas, N., Lestari, P., Ma, Z., Vanderlei Martins, J., Quel, E.J., Rudich, Y., Salam, A., Tripathi, S.N. Yu, C., Zhang, Q., Zhang, Y., Brauer, M., Cohen, A., Gibson, M.D., and Liu, Y. SPARTAN: A Global Network to Evaluate and Enhance Satellite-Based Estimates of Ground-Level Particulate Matter for Global Health Applications. Atmos. Meas. Tech. 2015, 8, 505-521.

Tryner, J., L’Orange, C., Mehaffy, J., Miller-Lionberg, D., Hofstetter, J.C., Wilson, A., Volckens, J., Laboratory evaluation of low-cost PurpleAir PM monitors and in-field correction using co-located portable filter samplers. Atmospheric Environment 220 (2020) 117067.

Zheng, T., Bergin, M.H., Johnson, K.K., Tripathi, S.N., Shirodkar, S., Landis, M.S., Sutaria, R., Carlson, D.E., 2018. Field evaluation of low-cost particulate matter sensors in high and low concentration environments. Atmos. Meas. Tech. 11, 4823-4846. https://doi.org/10.5194/amt-114823-2018.

Zhou, Y., "2016 product data manual of PLANTOWER - PMS5003 series data manual,” https://www.aqmd.gov/docs/default-source/aq-spec/resources-page/plantower-pms5003manual v2-3.pdf, accessed 15 March 2021. 